\title{
Challenging Expectations: \\ Perceptions of Canadian Music and the Localized Practices of Experimental Artists
}

\author{
By
}

Joni Sadler

\begin{abstract}
A thesis submitted to the
Faculty of Graduate and Postdoctoral Affairs

in partial fulfillment of the requirements for the degree of

Master of Arts
\end{abstract}

School of Journalism and Communication

Carleton University

Ottawa, Ontario

(C) 2011

Joni Sadler 
Library and Archives

Canada

Published Heritage

Branch

395 Wellington Street

Ottawa ON K1A ON4

Canada
Bibliothèque et

Archives Canada

Direction du

Patrimoine de l'édition

395 , rue Wellington

Ottawa ON K1A ON4

Canada
Your file Votre référence

ISBN: 978-0-494-87790-6

Our file Notre référence

ISBN: $978-0-494-87790-6$

\section{NOTICE:}

The author has granted a nonexclusive license allowing Library and Archives Canada to reproduce, publish, archive, preserve, conserve, communicate to the public by telecommunication or on the Internet, loan, distrbute and sell theses worldwide, for commercial or noncommercial purposes, in microform, paper, electronic and/or any other formats.

The author retains copyright ownership and moral rights in this thesis. Neither the thesis nor substantial extracts from it may be printed or otherwise reproduced without the author's permission.
AVIS:

L'auteur a accordé une licence non exclusive permettant à la Bibliothèque et Archives Canada de reproduire, publier, archiver, sauvegarder, conserver, transmettre au public par télécommunication ou par l'Internet, prêter, distribuer et vendre des thèses partout dans le monde, à des fins commerciales ou autres, sur support microforme, papier, électronique et/ou autres formats.

L'auteur conserve la propriété du droit d'auteur et des droits moraux qui protege cette thèse. $\mathrm{Ni}$ la thèse ni des extraits substantiels de celle-ci ne doivent être imprimés ou autrement reproduits sans son autorisation.
In compliance with the Canadian Privacy Act some supporting forms may have been removed from this thesis.

While these forms may be included in the document page count, their removal does not represent any loss of content from the thesis.
Conformément à la loi canadienne sur la protection de la vie privée, quelques formulaires secondaires ont été enlevés de cette thèse.

Bien que ces formulaires aient inclus dans la pagination, il n'y aura aucun contenu manquant. 


\begin{abstract}
$\underline{\text { Abstract }}$
The discussion of Canadian music has traditionally been structured by numerous influences, including an emphasis on cultural policy and nationalistic ideals, which leads to a particular framing of the artist. This framing hinges on economic factors and seldom acknowledges the localized activity that is more focused on developing social, cultural, and symbolic capital within particular scenes. I argue that the artists working within these communities, particularly experimental musicians, are typically excluded from the dominant vision of Canadian artists. To challenge this framing, I suggest that it is necessary to reach out to the artists themselves to construct a model that incorporates the first-hand accounts from experimental musicians. Drawing from artist interviews, I claim that their lived experiences as scene participants points towards new understandings of Canadian music creation and the necessity of a more inclusive conception of the artist within the music industry and its surrounding discourse.
\end{abstract}

Keywords: Canadian music, experimental music, music scenes, independent music, cultural industries. 


\section{Acknowledgements}

This project would have been impossible without the help and support of many people. Sheryl Hamilton, who was patient enough to supervise this thesis through its multiple versions, deserves sincere thanks for all of her guidance and valuable feedback. The artists who agreed to share their stories with me provided constant inspiration and I cannot sufficiently express my gratitude for their openness and belief in this project. My parents, Kathy and Doug Sadler, who have constantly supported and encouraged my educational pursuits. Erin Flynn and my colleagues at CHUO 89.1 for being exceptionally accommodating during the writing process. All Lyon St. roommates and friends near and far for their enthusiasm and moral support. Blake Hargreaves for editing and insight. And finally, heartfelt thanks to the music community in Ottawa and all who contribute to it.

This thesis is dedicated to my great-aunt, Ms. Lucie Kinnear, who taught me the value of independence, creativity, and always questioning the rules. 


\section{Table of Contents}

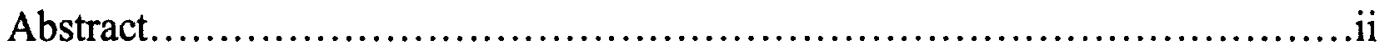

Acknowledgements.........................................................

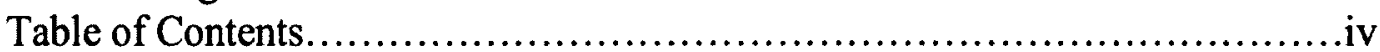

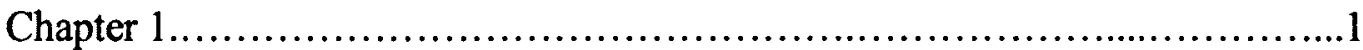

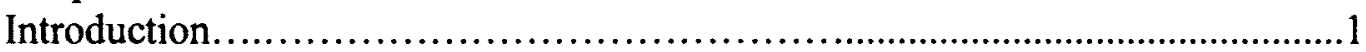

A Note on Language and Terminology ..............................................

Literature Review...........................................................4

A Look from the Ground Up: Independent Music Production in Canada...........5

A Bigger Picture: Canada's National Music Industry..........................10

The Longstanding Connection between Canadian Music and Policy

(And Why We Should be Critical of It) ....................................13

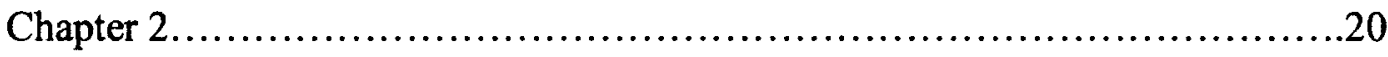

Conceptual Framework..................................................20

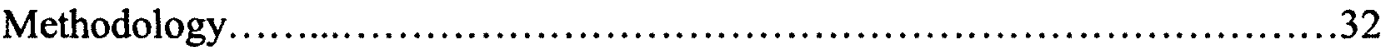

Setting the Stage: Framing the Field of Mainstream Production..................37

Chapter 3.................................................................49

Analysis of the Field of Restricted Production................................49

Community...............................................................50

Space..................................................................65

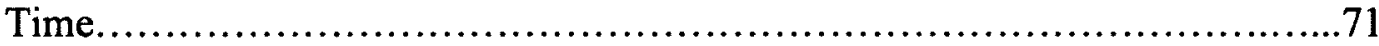

Releases: Aesthetics and Distribution..................................... 75

The Musicians' Lifestyle: Touring and its Impacts, On and Off the Road........85

A Summary: General Trends, and a Look Towards the Future..................89

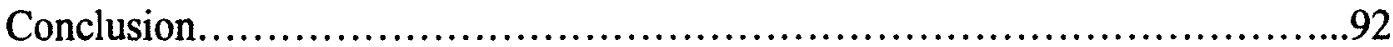

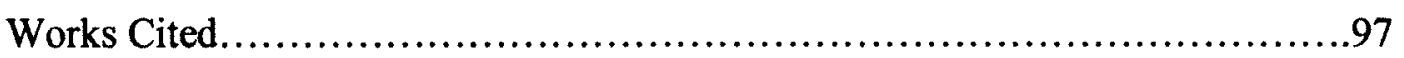

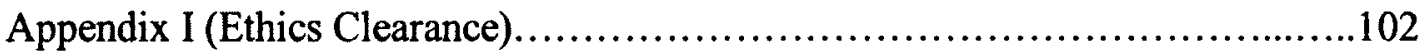




\section{Chapter 1}

\section{Introduction}

One night in the early $1990 \mathrm{~s}$, in a move that challenged both industrial norms and the sleepy reputation of its city, an Ottawa house venue opened its doors to a pair of local hardcore bands that had just returned from a long tour. It was 1:00 AM. After a resident of the house okayed the plan with his neighbors, the bands started to play. A hundred and fifty kids showed up and packed themselves into the one-room building, going outside silently between sets to smoke. Nobody alerted the police. An American musician who had played to an empty version of that same room earlier snidely questioned the impromptu but wildly popular gathering that had formed. Upon hearing this comment a member of one of the local bands put down the amp he was carrying and said, with more than a little vitriol in his voice, "We got our own music in this town. We don't need you."1

This example of an underground cultural practice allows a glimpse into a type of scene that is seldom included within the dominant discourse surrounding the Canadian music industry. The venue itself, the strong sense of community between artists and the audience, and the attitude of resistance combine to ground an alternative conception of how music is produced and consumed. It poses a challenge not only to the preconceptions held by the foreign artist but also to many of the dominant tropes of the industry through its highly autonomous logic and its total detachment from the cultural policy that structures so much of the academic literature covering Canadian music production. I

\footnotetext{
${ }^{1}$ From an interview with Brian, who lived in that particular house and helped to coordinate the show.
} 
argue that the story of experimental, non-mainstream artists remains a largely untold story in considerations of Canadian music and in the policy discourses that support and help to define the national industry. This thesis begins to tell that story by talking to some of these artists about their musical practices and how they order and imagine them.

I aim to demonstrate that there is a disconnect between the vision of the artist that exists within the dominant discourse surrounding Canadian culture and the actual realities faced by musicians who work in aesthetic styles that fall outside of mainstream tastes. The framing of artists within the Canadian music industry and the literature surrounding it paint the picture of a certain type of creator at the cost of excluding musicians who do not partake in particular accepted activities or norms. Ultimately, my goal is to shed light on the way these individuals function as cultural creators in hopes of developing a greater understanding of how they survive economically and what is relevant to them in terms of their musical activities. This, in turn, can increase the dialogue surrounding different forms of cultural production to allow for a more inclusive vision of Canadian musicians and the variety of struggles, rewards, and experiences that make up their lived experience.

\section{A Note on Language and Terminology}

Within this study, I frequently use certain terms relating to various acts of cultural production. In order to remain consistent with the language used by the majority of the academic discourse, I refer to the musicians within my study as artists. By including the participants within the term most frequently used within policy and academic language, I 
pose a challenge to its traditional use and any implicit sense of exclusion that it has historically embodied.

Additionally, I use the term experimental to describe the aesthetics with which the artists in my study work. While the aim of this study is not to focus on a particular genre but rather to foreground the experiences of artists functioning outside of mainstream audience tastes, I try to avoid phrases that are specific to any unique style. The term "experimental" can encompass a very wide variety of music; in the context of this paper, I use it as a general descriptor that accounts for abstract electronics ${ }^{2}$, noise rock $^{3}$, drone $^{4}$, and the multitude of other sub-genres in which the participants engage. Its use within the paper is not meant to signify specific aesthetic or sonic qualities, but instead to reinforce the fact that the music being discussed does not fall within the paradigm of established pop, rock, or other mainstream musical traditions.

\footnotetext{
${ }^{2}$ Electronics projects often characterized by minimal structure and abrasive or noisy elements, frequently resulting from the incorporation of home-made or modified synthesizers and other electronic instruments. Pan Sonic and Pole are two well-known artists from this style. See http://allmusic.com/explore/style/experimental-electro-d3045
}

\footnotetext{
${ }^{3}$ Bands using some traditional elements of rock music (typically guitars and/or percussion) combined with high levels of distortion, harsh vocals, and dissonance. Sometimes confrontational and highly theatrical in a live setting. Examples of contemporary American noise rock bands include Hair Police, Mouthus, Sightings.

${ }^{4}$ An aesthetically minimal style consisting of sustained notes or other musical elements. Drone pieces are typically lengthy with little variation throughout the composition, and can range from either high and shimmery to very heavy and sludgy-sounding. See http://en.wikipedia.org/wiki/Drone music.
} 


\section{Literature Review}

As a general trend, the literature surrounding the production of music in Canada is marked by a high degree of interconnection with the discourse focusing on cultural policy. The close ties between these fields result from a history in which cultural policy has been used to shape and influence the mainstream music industry in significant ways. The specific nature of Canadian music production has also contributed to this scenario: the strong protective measures that have been enacted against foreign, particularly American, influences facilitate the perception that Canada's music industry is wellsupported by various federal initiatives. However, much of the discussion surrounding Canadian music and nationalist cultural policy fails to question the potentially problematic nature of their implied codependence. Since policy shapes so much of the overarching discussion of the Canadian music industry, this issue is significant because it plays such a key role in how the nation's music production is viewed on a large scale.

In order to analyze the dominant framing of Canadian musicians and the larger industry in which they work, I divide the existing literature into three main categories: works that focus on the sphere of independent music production within Canada, the national music industry as a whole, and finally the discussion of cultural policy in relation to the music industry. What this structure aims to demonstrate is that there is a dominant cultural logic which understands artists in particular ways and that the fields of music production and policy are intertwined. By placing the musicians themselves at the forefront of my analysis, my goal is to reinforce their position as key elements within the process of cultural production and to determine whether the current literature surrounding 
music industries in Canada takes adequate account of them. As well, the analysis will highlight the language used to discuss musical production and how it is framed alongside -- or as a subset of -- the logic of cultural policy.

\section{A Look From the Ground Up: Independent Music Production in the}

\section{Canada}

The literature focusing specifically on the production of Canadian media that stands apart from larger policy discourse is fairly limited (Wagman, 2010, p. 621). Within the majority of the work surrounding the musical components of the country's media production, a model of the artist is constructed: an individual who displays the desire for a modest amount of success while still maintaining a sense of nationalistic pride in the larger Canadian music scene. Scott Henderson (2008) describes the success of artists as their ability to "interact, contribute to and promote each other's work, and help to build a Canadian scene that can be confident without being overly self-conscious" (p. 314). Groups such as Broken Social Scene and the Arcade Fire, both of whom have received significant amounts of critical and commercial success within the past decade, are often used as examples of the type of success that artists strive for within the dominant discourse surrounding music production (Henderson, 2008, p. 313). These bands display certain characteristics that make them ideal models for flaunting the success of Canada's musical producers: they are framed by the dominant cultural logic as having earned widespread success through grassroots efforts while maintaining a balance between artistic integrity and commercial appeal. This leads to their frequent reference 
within mainstream discourse as examples of successful cultural infrastructure and the opportunities this can provide ${ }^{5}$.

According to the dominant logic of independent music production, artists and industry members engage in a variety of normative practices to achieve certain outcomes. For example, receiving commercial radio airplay and filming a successful music video are two of the steps frequently described that lead to success within the music industry ${ }^{6}$. However, these activities subscribe to a specific model of success that may not include those members of certain independent scenes ${ }^{7}$. The framing of the music industry within the dominant discourse serves to reinforce the economic and nationalistic forces that are perceived as being the primary motivators behind the creation of music. Additionally, the practices in which artists themselves engage are rarely discussed without being accompanied by policy talk. This omission results in a distinct lack of knowledge of how artists actually survive in Canada, since the constant focus on the policy aspects of production lead us away from questions regarding how artists create their work and the financial struggles they may face (Wagman, 2010, p. 626).

\footnotetext{
${ }^{5}$ See http://www.thestar.com/article/865466--part-3-canadian-pop-music-may-well-have-outgrowncancon-rules.

${ }^{6}$ See "Task Force on the Future of the Canadian Music Industry" Section 2.5b (Ekos Research Associates Inc.) for an example of how radio and video have traditionally been portrayed as valuable tools for the successful promotion of Canadian artists. Alternately, Tobias van Veen provides a more critical response to this trend in his essay "Fuck Art, Let's Dance" (pg. 15, published in FUSE 26.3 (2003).

${ }^{7}$ For a detailed account of Canadian independent music scenes, see Andrew Vincent's Making Scenes: Studying Local Independent Music in Canada (2005).
} 
While the model of independent music production constructed by the dominant logic of the industry serves as the reality for many musicians and industry workers, the vision of the artist that is framed by its logic does not necessarily include those working in styles which lack the emphasis on building a national "scene" or accumulating economic capital. Like Wagman, Andrew Vincent (2005) recognizes the tendency for the discussion of Canadian music to be strongly tied to policy measures (p. 45). However, he goes on to provide a detailed glimpse into a particular indie rock community which highlights the lack of understanding most policy measures have of localized communication practices. This is a valuable addition to the discussion of the Canadian industry because it accounts for a variety of practices that impact, but are not necessarily related to, the production of music. Vincent also highlights the importance of noneconomic capital within independent communities, which aligns his paper with my argument that the framing of artists as largely economically-driven within the context of the national industry is not a wholly accurate model. Similar artist-driven accounts can also be found in Barry Shank's writing, particularly his analysis of the music scene in Austin, Texas. Like Vincent, Shank (1994) incorporates many personal narratives from the scene's participants into his study. This direct inclusion of cultural producers' voices provides a much richer account of the factors which structure their lives, such as how they are able to make their livings (Shank, p. 164). However, while Shank's study is valuable given its status as one of the first in-depth looks at a North American musical scene, Vincent's work is even more important as a point of reference to my research due to its rooting within a Canadian environment and the author's acknowledgement of the 
unique implications of this positioning. As such, Vincent's study provides one of the few accounts of Canadian music that looks at the industry primarily through the lens of community members instead of policy analysts and makes an effort to include many firsthand accounts from the artists on whom the research focuses.

Another Canadian scholar who takes issue with the traditional vision of the artist within mainstream cultural logic is Tobias van Veen (2003). He uses the example of techno music to demonstrate how certain practices or attitudes contained within the traditions of a genre can lead to isolation from the supposedly inclusive model of Canadian artists as they are envisioned by the dominant discourse. He explains that the quantity of most experimental electronic releases (generally pressed in runs of 500-1000) is too small to be recognized as truly legitimate in the eyes of the dominant cultural discourse. At the same time, the process used to create this music is misunderstood since it differs from the traditional studio recording methods used by most rock and pop bands (van Veen, 2003, p. 14-15). Solo electronic artists or collectives function according to a different work style, and their habits do not seem to be as widely supported or recognized in comparison to mainstream rock-based projects. This indicates a lack of knowledge and understanding about the way they produce their music and ruptures the understanding of artists as they are typically framed within the dominant discourse of cultural production. Van Veen and his colleagues at the MUTEK 2002 conference in Montreal came to the conclusion that "what is needed is a recognition of the in-between or liminal status of experimental electronic music among institutional knowledges and practices as well as within the funding bodies" (van Veen, 2003, pg. 17). This call for recognition does not 
only apply to artists working with electronics -- I argue that the same pattern can be observed in many other niche and experimental styles of music. As a result, this trend of misunderstanding between certain musicians and the institutional organizations that structure the dominant logic contributes to the difficulties that these artists experience in gaining both support and understanding for their work. My project attempts to answer, in part, that call.

In addition to this general lack of understanding of the nature of their work, there are certain unique practices in which independent artists take part that are not always recognized within the larger discussion of Canadian music. Artists who are committed to establishing and maintaining a strong sense of creative autonomy instead of aiming for the success demonstrated by bands like the Arcade Fire may also find themselves excluded from discussions of independent music production because many of the choices they make as cultural producers are not understood by dominant institutions. For example, struggles for autonomy can be seen in the choice of format used to release music. The most obvious example of this is the use of cassette tapes since they not only reject the standard formats accepted by the mainstream industry (vinyl and, later, CDs and digital downloads), but they also put much greater control into the hands of the creator (Jones, 1990, p. 75). Other conventional methods of trying to preserve autonomy through subversion of industry standards include selling albums or 7" singles for a fixed maximum price, not including bar codes on products, and refusing payment by credit card (O'Connor, 2008, p. 73). Artists who embrace these practices also tend to perform in spaces that foster autonomy over commercial gain such as squats, lofts, and basements 
(Russell, 2009, p. 89). While the typically small size and less formalized nature of these venues often results in minimal financial gains, artists are conversely able to build upon their cache of cultural capital and thus strengthen the sense of autonomy that they strive to maintain.

These scholars' use of the language of autonomy and alternative practices, however valid it may be in some respects, also signals the risk of romanticizing the artist. The favoring of autonomy in the production of art frequently defaults to a scenario in which the creator is discussed in an overly romantic or esoteric framing. It can blunt critical analysis. In turn, this can lead to an idealization of their practices that disregards tensions or the conscious sense of performance contained within their activities. With this in mind, it can still be suggested that the key point to take away from Alan O'Connor and Bruce Russell's examples is that the practices frequently performed by highly autonomous musicians do not fit into the typical scholarly framing of the musical artist, and as a result both these events and the musicians who participate in them are frequently rendered invisible.

\section{A Bigger Picture: Canada's National Music Industry}

According to much analysis of the national music industry, one of its defining elements from a historical standpoint is its reactions against the perceived threat of American mass culture. In the context of music, Reebee Garofalo (1991) traces the notion of "cultural domination" to the early 1900 s when the major American recording firms Edison, Berliner, and Columbia developed Canadian subsidiaries which dominated the 
majority of the national market (p. 328). During the 1970s, tariffs against imported goods have contributed to the foundation of branch plants which led to the "domination of the Canadian industry by non-Canadian repertory" (Bennett, 1993, p. 57; Straw, 1996, p. 98). Branch plants are facilities which are owned and controlled by American forces yet account for a large amount of the record production that occurs in Canada. According to Robert Wright (1991), all of the major companies within the music industry established branch plants due to Canada's relatively high tariffs on imported recordings and have gone on to exert significant control over the national marketplace since their introduction (p. 307).

This phenomenon of American "domination" and the fear of its consequences has continued over the past century and has remained a constant element within the overall narrative surrounding Canadian music production. Garofalo (1991) suggests that the role of distribution within the national industry has become another area in which tensions between the two countries are felt. He claims that the lack of a strong Canadian distribution system has perpetuated the force initially demonstrated by American record companies and thus made it more difficult for Canadian artists and labels to compete ( $\mathrm{p}$. 328-29). Many of the American branch plants went on to establish their own distribution structures, which made it even more challenging for Canadians to found a strong distribution network of their own (Straw, 1996, p.102). This pattern was solidified during the 1970s and, according to Straw (1996), has continued functioning in much the same way ever since (p. 102-103). 
The power exerted by the American music industry has typically been framed as a threat within the overall discourse of the field and over time it has become a defining element in the discussion of Canadian music production. Vincent (2005) suggests that "when Canadian music is considered, it is almost always done so in terms of its position with respect to the worldwide industry and in particular the United States" (p. 44). Its influence is generally interpreted as a force which has the potential to stifle the development of a homegrown Canadian music industry. One of the most "dangerous" elements of U.S. cultural domination, according to some scholars, is the risk of American aesthetics drowning out traditional Canadian forms or influencing artists to make music that is more appealing to U.S. audiences in hopes of "making it" within the international scene (Grenier 1990, Wright 1991). Through the adoption of American radio formats and musical styles, Line Grenier suggests that "in one way or another, Canadian formats reflect American consuming tastes and habits, if not American musical styles" (p. 223). In a similar manner, Eric Spalding (2008) claims that the establishment of foreign subsidiaries which had enough resources to promote stars who were already famous in their home country rendered it even more difficult for Canadian artists to compete (p. 147). This concern over the implications for Canadian artists is also echoed by Wright (1991), who argues that our nation's role has traditionally "been to serve as a market for mostly non-Canadian recordings of non-Canadian musical performances" (p. 307). These claims suggest that the discourse surrounding the national music industry frames any significant involvement from international forces and the subsequent influence they may have as a threat towards Canada's industrial and cultural institutions. Consequently, this 
results in the fear that any unique nationalistic qualities inherent in Canadian music, tropes through which both artists and audiences can express their Canadian-ness, may be subverted through the effort to succeed in the American industry.

\section{The Longstanding Connection Between Canadian Music and Policy (And Why We Should be Critical Of It)}

This fear of outside influence on the homegrown music industry has contributed to the formation of cultural policies surrounding music. While not all policy initiatives have been met with positive responses from those within and outside the industry, the discussion of policy within the workings of Canadian music is almost omnipresent. Wagman (2010) argues that this reliance on policy within the discussion of cultural production is not restricted to music, but applies to Canadian media production more widely (p. 620). The majority of analysts view cultural policy measures in the context of the music industry as at least somewhat beneficial. This attitude stems from the notion of cultural protectionism resulting from the assumed threat of international, particularly American, cultural influence. According to this perspective, policy initiatives can play a dual role: not only do they foster an increase in the quality and quantity of Canadian cultural goods, they can also facilitate greater involvement in a marketplace that is overpowered by the force of the American industry. Analysts who support the idea of policy as a means of encouraging greater Canadian cultural production (Wagman 2001, Henderson 2008, Edwardson 2008) argue that cultural funding and the inclusion of more Canadian content in radio and television broadcast helps to stimulate the national industry by providing increased opportunities for artists. 
According to Marc Raboy (2006), the end of the First World War signaled the point at which broadcasting established itself as a consumer medium, and it also coincided with the introduction of the idea that "the state could and should be used as a progressive instrument of intervention for social purposes" (p. 300). This interventionist attitude is evident in the Canadian content quotas that are applied to radio stations across the country. Since the introduction of these quotas (generally referred to as "Cancon" percentages) in 1971, musicians who had previously been ignored by station owners in favor of foreign recordings became included within programming schedules, ultimately resulting in newfound exposure and increased popularity (Edwardson, 2008, p. 266).

The practice of regulating content to ensure a Canadian presence on the airwaves is a topic of frequent discussion in the analysis of the national music industry, and it is generally regarded by academics (as well as many industry workers) as a relatively positive and effective policy move. In support of this initiative, Spalding (2008) claims that "it is generally acknowledged that obligating radio stations in Canada to carry a certain percentage of Canadian music has had a favorable impact on the sound recording industry, helping Canadian artists to be heard more often on the radio" (p. 146-47). The introduction of Cancon quotas is also thought to be responsible for the creation of new studios, manufacturing plants, and the introduction of more industry employees in order to meet the newly-recognized needs of Canadian artists (Edwardson, 2008, p. 266). Brian O'Shea Papizzo (1994) provides a tidy summary for much of the academic literature by stating that "overall, the general consensus of both the Canadian radio and recording 
industries is that CanCon regulations have accomplished what they set out to do, which was to create a space for Canadian music on its own airwaves" (p. 138).

While this positive response towards policy initiatives is fairly widespread throughout much of the academic literature analyzing the Canadian music industry, there are also analysts who are more critical of these policy interventions. Some argue that policy initiatives can potentially benefit the industry, yet they need serious revision from their current state in order to be fully effective (Mauws 2000, Crean 2000, Straw \& Sutherland 2007, Berland \& Straw 1995, Lorimer \& Gasher 2004). Many of the criticisms targeted towards music policy are directed at the different forms of funding that are available for the creation and dissemination of musical works. In an analysis of provincial music funding (The Manitoba Film \& Sound Development Corporation, 2000), Michael Mauws (2000) criticizes the ways in which funds are distributed: "It seems to suggest that the fate of the cultural products is rarely decided by their own intrinsic quality" (p. 243). Mauws suggests that factors other than artistic merit can influence judges' decisions, which can become problematic in the allocation of grant funds depending on the mandate of the cultural organization. For example, his research demonstrates that the lack of a distribution deal results in an artist being less likely to be successful in his or her application (p. 236).

Another criticism of current policy support mechanisms is that they tend to "[reward] most favorably those who manage and administer, produce, distribute or market art and culture rather than those who make it" (Crean, 2000, p. 202). In this sense, the artists themselves are some of the least likely in the production process to reap any 
financial benefits of policy initiatives. Federally-run cultural funding bodies have also come under fire from certain analysts due to disjunctures between their mandate and their actions, their decision-making processes, and the variety of structural elements that influence the way they function as organizations.

In an analysis of the $\mathrm{FACTOR}^{8}$ funding system Papizzo (1994) suggests that because there is a significant presence of commercial radio executives on the foundation's Board of Directors, mainstream appeal has become an important deciding element in determining who receives support (p. 145). However, this observations stands at odds with the language of inclusion that FACTOR uses when presenting itself to potential applicants. Since many musicians do not possess the commercially-appealing qualities that FACTOR looks for, its self-portrayal as a policy initiative that offers support to all artists is rendered somewhat misleading (ibid.). The rhetoric used by FACTOR to describe its role in the process of musical creation paints it as an institution that is wholly supportive of all artists: "Whether an artist is looking to record a demo, full length sound recording, market and promote an already existing album or showcase and tour domestically and internationally, funding is available" (www.factor.ca, "About Us"). The framing of this statement and the promise of financial support, regardless of an artist's objectives, indicates a sense of inclusion that would not discriminate on the basis of genre or aesthetic choices; however, it is stated elsewhere that applications are judged based on the "artistic merit and potential marketability of the project" (FACTOR 2010-

\footnotetext{
${ }^{8}$ The Foundation Assisting Canadian Talent on Recordings, or FACTOR, was founded in 1982 and its primary role is to administer funds to Canadian artists and the national music industry. Originally foundedas a means of bolstering the Canadian music industry to help radio broadcasters meet their Cancon requirements, it has since expanded to fund a range of practices within the music industry, such as touring and marketing. See http://www.factor.ca/AboutUs.aspx for a self-written description of the organization's role in the national industry.
} 
2011 Annual Report pg. 38). What this indicates is that FACTOR is perhaps overstating its true accessibility to all artists, or else it has developed a model of the artist which does not fully account for individuals working in less mainstream genres or whose ultimate goals may lie in areas other than mass record sales and widespread international popularity.

On a larger scale, scholars have also suggested that the international nature of the music industry results in a devaluing of policy regulation such as Cancon quotas. Robert Wright (1991) suggests that since Canadian artists must develop international appeal in order to have a chance at widespread success, interventionist policies do not necessarily assist artists because they would ultimately need to sign with an American label regardless (p. 312). "No interventionist policy will enable Canadian record companies to compete with the multinationals internationally; on the contrary, there is strong evidence to suggest that official protectionism has limited the ability of indigenous companies and artists to compete outside of Canada" (Wright, 1991, p. 314). Related to this idea is the notion that, despite any good intentions, policies which aim to professionalize the culture and production of music will always receive at least some criticism for interfering with a process that is best left on its own (Straw, 2000, p. 177). While Wright does make a valid point, his argument also assumes the desire of a certain kind of success which may not be shared by all Canadian artists. Are they even interested in signing to American labels? Also, like the majority of discourse focusing on Canadian musicians, his arguments spend just as much time -- if not more -- discussing the ramifications of policy measures as opposed to the actual realities that artists face. 
Within much of the discussion surrounding Canadian music, policy measures and the national industry are so interconnected that it becomes difficult to isolate the industry and the artists who work within it from the overarching frame of cultural policy. This is a problematic tendency because policy formation does not dictate or encompass the production of music; on the contrary, much of its focus towards establishing the success of artists within mainstream or international arenas necessarily excludes musicians who do not share those goals. A particularly troubling result of this is the fact that the media and cultural industry's dependence on policy is frequently accepted as a default analytical position, which can result in the exclusion of key elements or processes within cultural production (Wagman, 2010, p. 625). The strong focus on policy measures has led to an underdeveloped analysis of certain facets of the industry, such as the lack of data drawn from the industry and the sparse number of primary accounts from actual cultural producers. Much of the policy influence on the music industry stems from the perception that it is necessary to protect the Canadian industry from international, especially American, forces, and this fear of outside influence is also an important element in the framing of the industry within a significant amount of its surrounding discourse.

The analysis of the literature focusing on the Canadian music industry raises a number of questions: what implications might the perceived interconnection of musical creation and cultural policy have for artists who do not fit into the aesthetic and industrial models that policy organizations promote? What voices are misunderstood, or left out altogether? How are the perspectives of the musicians themselves included within the discourse, if they are at all? Does the fact that the academic literature surrounding artists 
is so strongly influenced by industrial concerns pose any problems? In order to address these questions, I aim to shed some light on first, non-mainstream realms of music production and second, the specific views and experiences of some of the artists who engage in this alternative production process. 


\section{Chapter 2}

\section{Conceptual Framework}

My focus on creative production in the area of non-mainstream music and specifically on the experience of artists requires me to concentrate on issues tied to the production of value. Given that one of the main issues resulting from my analysis of the academic literature is its emphasis on industrial and economic factors in the mainstream industry, it is necessary to build a model that could begin to account for other types of capital or gratifications in addition to the financial aspects of the creative process. To accomplish this goal I mobilize Pierre Bourdieu's concept of the field of cultural production, which proves to be a very useful tool in the discussion of musical creation. A field of cultural production is defined as "a network of social relationships that is organized around a particular practice and is relatively autonomous from the social structure at large" (Moore, 2007, p. 440). In other words, it is "the system of objective relations among different instances, functionally defined by their role in the division of labour of production, reproduction and diffusion of symbolic goods" (Bourdieu, 1993, p. 115). Bourdieu refers to the field as "the structure of the distribution of the capital of specific properties" which can, in turn, determine the degrees and types of success (whether they be economic gains, prestige, etc.) that can be obtained by those within the field (1993, p. 30). One of his suggestions about the field that makes it most applicable to the study of contemporary music is the notion that many of the positions within the field are "elastic and undemanding." Since they do not require the high levels of economic or educational capital demanded by other fields, cultural production is an area which attracts 
a wide variety of participants who can occupy any number of fluid and diverse roles (1993, p. 43).

Bourdieu (1993) claims that there are different types of fields through which cultural goods can be produced, generally broken down according to the activities of their participants. The field of large-scale cultural production is structured so that it creates goods for an audience whose members are not themselves cultural producers (in other words, the greater public body). In contrast to this, the field of restricted production aims its goods towards a smaller audience generally made up of other creators and consequently the criteria for evaluating goods that emerge from a restricted field of production are different from those associated with a larger field, creating a sense of privilege for those who are dealing with the more restricted of the two (Bourdieu, 1993, p. 115). Works generated within the restricted field of production are said to be pure, abstract, and esoteric in their nature. By purity, Bourdieu is referring to the unique qualities of these works that results from the fact that they require their audience to possess a specific aesthetic disposition tied to an understanding of the principles of the goods' production (1993, p. 120). These "works of restricted art owe their specifically cultural rarity, and thus their function as elements of social distinction, to the rarity of the instruments with which they may be deciphered" (ibid.). In this sense, the field of restricted cultural production provides a fitting model for the study of experimental music. Since this type of music demands a specific and somewhat unusual knowledge or aesthetic appreciation from its audience in order to be fully understood, Bourdieu's 
model helps to shed light on the different factors which can impact the creation of niche musical genres.

Bourdieu's recognition of different types of capital is one of the reasons why his concept works particularly well in the analysis of cultural goods that fall outside of mainstream audience tastes and economics. He defines capital as "accumulated labor (in its materialized form or its 'incorporated, embodied form) which, when appropriated on a private, i.e., exclusive, basis by agents or groups of agents, enables them to appropriate social energy in the form of reified or living labor" $(1986$, p. 46). In order to fully account for the activities of a cultural field, he breaks down capital into more specific forms, which are defined in his essay "The Forms of Capital":

Economic capital, which is immediately and directly convertible into money and may be institutionalized in the form of property rights; cultural capital, which is convertible, on certain conditions, into economic capital and may be institutionalized in the form of educational qualifications; and as social capital, made up of social obligations ('connections'), which is convertible, in certain conditions, into economic capital and may be institutionalized in the form of a title of mobility (1986, p. 47).

Two years prior to this explanation of capital, Bourdieu also included the notion of symbolic capital in his book Distinction (1984). He defined this as the sense of competence and authority that can be invested in one's image (p. 291). The breakdown of capital in this manner allows for a more comprehensive understanding of cultural production since it allows the value of a good or practice to be measured in ways not necessarily rooted in economics.

Cultural capital has been used fairly extensively in the discussion of musical production. Depending on the circumstances, it can be acquired without any conscious 
efforts by an individual and its ephemeral state renders it specifically tied to a certain holder; in other words, it cannot be passed down from one person to another in the same manner as economic capital (Bourdieu, 1986, p. 49). This way of measuring capital is particularly useful for the analysis of musical activity since it attributes value to the approved tastes, values, or knowledge that circulate through a field (Bourdieu 1984, p. 291). Closely tied to this, the related notion of symbolic capital can be used to measure the prestige or status associated with a good or activity (ibid.). In this sense, symbolic and cultural capitals are useful in measuring the value of artistic works. For example, in the case of music, they can help to explain the value attributed to a limited-edition record with elaborate visual packaging. While it may not possess high levels of economic capital according to the larger market, its restricted quantity and accompanying visual or tactile element serves to elevate its symbolic capital for those who possess the sense of cultural capital necessary to decode the value of these characteristics.

In addition to these understandings of value, Bourdieu (1986) also uses the notion of social capital to help account for the circulation of capital through various fields. Social capital is defined as:

The aggregate of the actual or potential resources which are linked to possession of a durable network of more or less institutionalized relationships of mutual acquaintance and recognition - or in other words, to membership in a group which provides each of its members with the backing of the collectively-owned capital, a 'credential' which entitles them to credit, in the various senses of the word (p. 51).

Bourdieu explains that social capital is accumulated and measured through the number of connections an individual has to others, and the amount of capital (whether it be economic, symbolic, or cultural) those connections possess (ibid.). In the context of a 
music scene, for example, social capital may be derived by establishing personal ties with an artist whose releases are perceived as being symbolically valuable. Within my research, I will mobilize this notion of social capital as a way to account for the flows of positive communication, interpersonal connections, and feelings of support that circulate through different musical scenes. Since I am focusing on what Bourdieu would classify as fields of restricted production, the ability to discuss the social connections between artists and other participants within the field alongside symbolic and cultural capital will be of significant importance in facilitating a more thorough understanding of what bonds exist between musical producers and consumers and how the value of these connections is measured.

Another valuable aspect of Bourdieu's theory in relation to the discussion of nonmainstream music is his stress on the element of autonomy within the field of production. He suggests that there is a constant struggle within a field between the forces of autonomy and heteronomy. In The Field of Cultural Production, Bourdieu (1993) defines heteronomy as the result of a demand for goods, whether that takes place via a specific patron or a larger market force, while autonomy within a field of restricted production can be determined by measuring its ability to define the criteria used for the production and judgment of its goods (p. 45; p. 115). By functioning as a specific market, a field can generate "a specifically cultural type of scarcity" and a value that is not strictly tied to economic value and physical scarcity of the goods, thus contributing to the level of autonomy associated with that particular good (Bourdieu, 1993, p. 117). Because cultural production deals primarily with symbolic goods as opposed to strictly commodities, these 
goods possess both cultural as well as commercial value. The two value systems can have varying degrees of independence, although a product's economic struggles may result in the reinforcement of its success as a cultural good. Consequently, those who abide by the autonomous principle often interpret mainstream or economic success as a sign of artistic compromise (Bourdieu, 1993, p. 113). Building on the idea of tensions between the two principles, Ryan Moore (2007) suggests that many of the struggles that occur within a field emerge between those who wish to preserve its autonomy and those wanting to absorb it into a larger, more dominant economic and political system (p. 440). In this scenario, one end of the struggle is represented by the heteronomous logic of the market which measures success through judging commercial sales and recognition from known authorities, while autonomous art dismisses the goal of monetary profit at the risk of compromising artistic integrity (ibid.).

According to Bourdieu (1993), the transactions which may take place within wholly autonomous fields of production can be reduced to a systematic inversion of the basic principles of all ordinary economies: if the only audience being targeted is other producers, then the economy is based on the general notion of "loser wins" (p. 39). This conscious embracing of financial failure is seen as a reinforcement of an artist's autonomy through the rejection of normative economic goals. Bourdieu (1993) claims that this is a form of disinterestedness which, as originally suggested by Max Weber, "demonstrates its authenticity by the fact that it brings in no income, a heretical break with the prevailing artistic traditions proves its claim to authenticity by its disinterestedness" (p. 40). Elsewhere, in Distinction, Bourdieu (1984) devotes further 
discussion to the two ends of the economic/cultural spectrum between which a creative work can fall. "The refusal of what is easy in the sense of simple, and therefore shallow, and 'cheap', because it is easily decoded and culturally 'undemanding', naturally leads to the refusal of what is facile in the ethical or aesthetic sense, of everything which offers pleasures that are too immediately accessible and so discredited" (p. 484). Artists working in more experimental styles embrace this attitude, producing works which may be more aesthetically challenging and thus appealing to a narrow instead of mainstream audience, and it is these artists on whom I am most interested in focusing in terms of how they understand the various elements of their field.

The concept of the field, including the autonomous and heteronomous logics that circulate within it, is an ideal model for mapping out the intricacies of the music industry. Moore (2007) employs Bourdieu's autonomous principle in his studies of punk and its offshoot styles, such as indie rock, because "although musicians must pursue economic capital to some extent to subsist, their primary motivation is to accumulate symbolic capital by creating music whose quality and significance is recognized by a community of their peers" (p. 453). In a different study of punk music, Alan O'Connor (2008) uses this same logic, claiming that "within the small-scale sector of cultural fields the rewards are not immediate economic success" (p. 17). Instead of aiming for financial gain, the artists working within these fields strive for recognition and appreciation from an audience comprised of members possessing a certain cultural knowledge, namely other musicians who are also familiar with the field. The degree to which those outside their limited sphere understand this motivating logic and the ways in which it can impact 
certain artistic choices can vary, yet it is an essential piece of knowledge for those interested in adding diversity and complexity to the analysis of the Canadian music industry.

While Bourdieu's model of the field of restricted cultural production provides a helpful model when dealing with autonomous cultural goods, I want to add further to it in order to negotiate the complexities of music production. Drawing many key elements from Bourdieu's concept of the field, Will Straw (2004) formulates the model of the "scene" to account for more particular elements that occur within specific musical cultures. The scene allows me to conduct an even closer analysis because of its specific understanding of musical practices (Straw, p. 412). He defines scenes as clusters of cultural and social activities that can be distinguished by either geography, the aesthetic styles of goods being produced, or any type of social activity that may form their basis (ibid.). Scenes can be fostered through a network of sites, such as record stores, and they have the ability to determine or perpetuate tastes and practices (Straw, 2004, p. 416). The recognized appreciation of these tastes can be seen as a mobilization of cultural capital as it was originally proposed by Bourdieu (1986, p. 49).

Drawing from Bourdieu, scenes often contain an elevated sense of autonomy that is displayed by artists as well as other individuals who participate in the production and consumption of music. For example, labels and media outlets such as fanzines are frequently known for specifically adhering to aesthetic or cultural values over business interests (Strachan, 2007, p. 252). In this scenario, the value of a release is measured 
primarily through its role as a successful creative artifact and its acceptance by a specific audience (for instance, the artist's peers) instead of its financial gain; as a result, the symbolic value of the text takes precedence over its economic measure (Strachan, 2007, p. 257). Another defining characteristic of a scene, particularly those which are comprised of styles falling outside the mainstream, is the tendency for artists to selfpublish their own work, organize performances, and write reviews -- in other words, taking control over the various stages of sound production (lles, 2009, p. 14-15). This activity among scene members can be seen as a manifestation of autonomous action in which individuals engage in all aspects of music creation instead of relying on the established mechanisms of the music industry to aid them with various stages of production.

Building on this notion of autonomy and self-publishing initiatives is the do-ityourself, or DIY, ethos that is present within many music scenes. According to this movement, the creation and promotion of music should not be limited to professionals in search of financial gain but instead is an open field embracing input from individuals whose desire lies in supporting creative and autonomous art that fall outside of the aesthetic boundaries of the mainstream media industries (Strachan, 2007, p. 254). Additionally, the DIY attitude favors self-publishing and involvement in various roles of the production cycle. In a discussion of noise music ${ }^{9}$, Anthony Iles (2009) claims that many artists not only perform and compose noise but also distribute other musicians' releases, organize concerts, and write about the creative form in publications. The whole

\footnotetext{
${ }^{9}$ Well-known names within noise music include Merzbow, Wolf Eyes, and Prurient. See Paul Hegarty's Noise/Music: A History and Mattin \& Anthony Iles (eds.) Noise \& Capitalism for detailed accounts of the genre.
} 
process "is about taking control over the production of sound -- its distribution and reception being very much a part of that production" (Iles, p. 14-15). Niche genres such as noise often function so far outside of the commercial nexus that many theorists have suggested their very existence hinges on the self-activity of their fans (Toth, 2009, p. 32).

Drawing from his studies on punk and indie rock, Moore (2007) suggests that this contemporary embodiment of Bourdieu's autonomous attitude fosters resistance and empowerment through particular actions and also contributes to forming an arena where individuals can exchange ideas and express their views, which often stand in opposition to social or cultural norms (p. 440). Through the adoption of this mindset, the independent record labels, artists and media outlets that make up a particular scene are able to foster types of creative expression that would not be welcome in more conservative mainstream arenas. Many of these outlets consciously encourage an attitude of wariness or resistance towards the commercial entertainment industry in addition to promoting cultural products that are too experimental or risky to be embraced by the mainstream entertainment industry (Moore, p. 457-58). "In both a practical and discursive way, small-scale cultural practitioners demonstrate that large media organizations do not necessarily speak 'for us all' and that, albeit in marginal ways, small-scale cultural production can add to the conversation of what is being said (or promoted) in the public sphere" (ibid.).

In this sense, the struggles over practices and the assertion of values within the institutions comprising a scene can serve as a contemporary re-thinking of Bourdieu's field. The factors that Straw incorporates into his idea of the scene -- a combination of 
institutions, attitudes and practices -- make it a useful tool for the framing of experimental music practices and the environments in which they take place. Straw's conception of the scene demonstrates the tension between various forms of capital that Bourdieu describes: participants can achieve success in the form of economic capital (such as record sales), cultural capital (for instance, the development of an approved sense of musical taste), symbolic capital (such as creating a record that is recognized as as an important cultural good) or social capital (developing valuable interpersonal ties with other members of the field). The recognition of these different types of capital also provide a more thorough overall understanding of the experiences lived by the artists, which can then be contrasted against the notion of the musician that is used by the dominant cultural discourse.

While Bourdieu's models provide a solid theoretical base for my research, there are certain elements of cultural production that his concept of the field neglects to address fully. The tensions that can arise between the economic and cultural gains, and the backlash they may cause against one another, are not fully explored in Bourdieu's work in a way that sufficiently accommodates contemporary music production. Another potential weakness that may result from Bourdieu's concepts, especially when analyzing the practices of autonomous musicians, is the risk of romanticizing the artist. This trend was noted earlier with the discussion of O'Connor's study and it resurfaces again with the use of Bourdieu's models of non-economic capital and autonomy. The esotericism occasionally displayed by artists as well as the discourse surrounding them can lead to a weakened analysis of the genuine realities they face. The key here seems to lie in finding 
the ability to describe and analyze certain artistic practices without glorifying them or the musicians who enact them. Straw's concept of the scene adds some depth to this discussion, which is why I employ his model as an addition to Bourdieu's field of restricted production. The scene is more specifically tailored to the production of music and thus allows for greater detail in the recognition of its particular components: the members, activities, institutions, and varying types of capital that circulate within it. At the same time, it provides a more textured understanding of the production of music that is less likely to result in the romanticization of scene participants.

Throughout the course of my interviews and their subsequent analysis, I made efforts to ground any findings within the context of the lived reality of the artist. By addressing different types of capital in combination with one another and situating the artists' experiences within the greater framing of the dominant cultural discourse, I was able to provide thorough accounts of the lived tensions these artists face while avoiding the risk of developing the romanticized notion of creative production. A description of the dynamics within particular scenes drawn from the artists themselves allowed for a rich understanding of the realities they experience and ultimately served to illuminate the tensions that arise between these accounts and what is promoted through the traditional framing of artists by academic and policy literature. 


\section{Methodology}

In the scholarly discussion of the Canadian music industry, there is a distinct lack of literature addressing the perspectives of artists themselves. A limited number of artists have had the opportunity to discuss their experiences in the literature that policy organizations publish about themselves, such as FACTOR's Annual Report ${ }^{10}$ and the Canada Council's official website ${ }^{11}$. However, these accounts are almost always drawn from creators who have received recognition amongst audiences and critics after receiving support (and thus acceptance) from cultural policy initiatives. Consequently, this frames them in a highly positive manner and demonstrates their success according to the logic employed by cultural agencies. Since the dominant logic employed in analysis of the Canadian music industry is so closely tied to the discourse of cultural policy, this structures an ideal type of musical success as well as defining certain practices which are implicitly deemed normal or appropriate. Artists who do not adhere to this overarching model are frequently misunderstood or worse, rendered invisible as a result.

Witnessing this phenomenon through the analysis of cultural documents, academic analysis, and my own observations as a musician and industry worker motivated me to investigate the issue further and attempt to give voice to some of the invisible artists while also trying to develop an alternative conceptual vocabulary to account for the specificity of their experiences. The differences between the few artists'

\footnotetext{
${ }^{10}$ Available under the heading “Annual Reports"on FACTOR's website: http://www.factor.ca/Documents.aspx

${ }^{11}$ http://www.canadacouncil.ca/aboutus/artistsstories/default.htm
} 
voices which are included within the literature on Canadian music and those which I experience in my own community prompted me to look at the ways in which musical production is understood within the larger cultural framework. The most obvious way to investigate this situation was, of course, to talk to musicians and determine how their realities compared to the model of the artist constructed by the dominant discourse. I used specific criteria in selecting musicians to participate in this research. First, I focused on artists who work in a style deemed to be outside of popular mainstream tastes. The goal here was not to focus on any specific genre, but to involve artists working in a variety of styles that do not fall within the aesthetics typically covered by the mainstream media and which are not ordinarily found in chain music stores. The important qualification is that the artists are creating music that is more experimental than what is typically favored by mainstream audiences and distribution networks, including commercial radio. Secondly, the artists needed to be willing to talk openly about their experiences as participants in a scene and how they go about creating their music. Since some of the discussion veered into more personal topics, such as financial struggles and how they are able to survive as artists, I needed to ensure that I was working with participants who would be open and honest in their responses. By keeping these two main criteria in mind, I was able to select a group of eleven artists who fit both qualifications and were willing to take part in the study. I used the snowball technique to gather this group of participants, building on the social relationships I had developed through my involvement with the local scene. My background in community radio and my own position as a musical performer led me to establish a strong network of fellow artists, and 
these connections allowed me to gather a diverse group of participants who were willing to engage in the study. Eight of the participants are from the Ottawa/Gatineau region, while the remaining three live in Montreal. Most of the initial contact with these artists explaining the project was conducted via e-mail and all interviews took place in person. I conducted the interviews in a variety of locations, both in Ottawa and in Montreal. I allowed the participants to choose the location of the interviews. Most took place in cafes, although some were held in the artists' homes. Each interview lasted approximately an hour and a half, and I transcribed all of the notes myself. In order to respect the confidentiality of the artists involved, all participants in the study remained anonymous and I used pseudonyms to identify them in the analysis. The ethics clearance form for the study is included in Appendix $I$.

While conducting the interviews, there were a number of factors that I consciously negotiated to ensure I was collecting data that would be sufficient in terms of quality and quantity. First, the use of a semi-structured interviewing technique allowed me to go into each interview with an outline of the basic information I needed from each artist while allowing for tangents and elaboration based on the artist's experiences. This allowed each interview to develop in a unique manner and made it easier for the participants to explain the particular elements which structure their scene and their creative process. To begin each interview, I asked for general background information about the participant's musical history as well as a description of the particular styles and instruments that he or she plays. Larry Z. Leslie (2010) suggests using these preliminary questions as a way to relax the participant at the outset of the interview before delving 
into more complicated questions (p. 126). While my introductory questions did serve that purpose, they also allowed the artists to describe their music in their own words. Since I am at least somewhat familiar with each of the participants' musical output, this prevented me from framing their creative work as I see it and instead let the artists discuss their music in the language that they felt was most fitting.

My closeness to the participants made for some unique advantages and challenges throughout the interview process. Because we are members of the same scenes, it was generally easy to make initial contact with the artists. They seemed quite at ease throughout the interviews, which may result from our previous social connections and the knowledge that $I$, the interviewer, am also a musician and supporter of local art. The mutual appreciation of certain types of music between interviewer and narrator and a shared involvement within local music scenes led the participants to be very open about their experiences and develop a sense of trust that may not have come as easily to a researcher who was an outsider to this environment. The major challenge that resulted from this, however, was the tendency for the artists to veer into overly conversational ways of discussing their experiences. This likely resulted from the fact that, since they saw me as more of an equal, they would slip into the colloquial language used between members of a scene that presupposes knowledge regarding certain practices. For example, particular sub-genres of music were brought up on at least one occasion. This is an example of a scenario where, as somebody who has served as the music director at a radio station for several years, I had the knowledge to decode the particular characteristics of that style; however, I needed to remind the artist to elaborate on the 
description of the music he was referring to in order for its use to still be valid to a reader who was not well-versed in that particular type of music.

The issue of bias was also a research factor that I was very cautious about. As a musician myself with a long history of activity in the local music scene, it was tempting at times to feel overly sympathetic towards the artists who participated in the study. Because their experiences were, in many cases, quite familiar to me, I needed to make specific efforts to maintain a scholarly distance as I conducted the interviews and analyzed the resulting transcripts. However, as Leslie (2010) states, our postmodern cultural environment nullifies any possibility of pure objectivity in research. Instead, he suggests that the best tactic is to "submit research activity -- from start to finish -- to careful scrutiny" through a careful examination of any research assumptions, theoretical concepts, and methods that are used within the study (p. 24). As a result, I paid close attention to these elements throughout the study to ensure that none of my research steps were presenting an unrealistic bias or romanticism towards the artists who are the focus of this project.

Once the transcripts were compiled, I proceeded to analyze them based on patterns found within the artists' narratives. While the participants represented diverse backgrounds, many of their experiences overlapped in various ways and this allowed me to combine unique instances into larger patterns or forces within the fields. Through the careful analysis of the interview material, I was able to develop a set of general trends that characterize independent music scenes as well as the realities they structure for nonmainstream artists, at least within the geographical regions covered by my research. 


\section{Setting the Stage: Framing the Field of Mainstream Production}

The economic and industrial motives that influence the framing of artists within much of the cultural discourse have elements that filter down and impact musicians. Both cultural policy and the national music industry contain perceptions of what constitutes legitimate artistic work that can be very narrow in scope, resulting in the possible exclusion of some individuals or creative practices. While this issue is seldom discussed, it remains a problematic element within the overall arena of Canadian culture. In the case of music, it tends to result in artists who produce work that is deemed to have at least some degree of mainstream appeal having the greatest access to resources and support.

These artists function within a realm that is made up of traditional elements of the music industry: striving for commercial radio play with a smash hit single, selling enough albums to make the charts, and playing in established music clubs (but dreaming of filling stadiums). Even a cursory look through the literature published by Canada's cultural policy agencies, such as FACTOR, demonstrates this pattern by highlighting the constant emphasis on artists who have achieved these goals ${ }^{12}$. This reinforces the normative, economically-driven idea of success as constructed by the larger cultural framework. The localized scope of my research sets it on a very different level from FACTOR's discussion of "stars" and mainstream popularity and thus renders any findings unable to fully challenge this framing of accepted success; however, what I aim

\footnotetext{
${ }^{12}$ An essay entitled "The FACTOR Story," published by the organization itself, makes multiple references to "stars" such as the country artists George Canyon and Aaron Pritchett. Both of these artists laud FACTOR for supporting them in studio recording and merchandising, among other activities considered standard within the mainstream industry (pg. 5).
} 
to show through my analysis is how certain scenes hinge upon this sense of locality and small-scale production and how the experiences of artists working at this level are frequently rendered invisible within the larger discourse of cultural production. By mapping out a preliminary version of the dominant field based on its understanding within discourse surrounding the industry, the differences between these two models will begin to emerge.

When analyzed through Bourdieu's theoretical lens, it becomes evident that his concept of the field of large-scale cultural production is a model that frames the mainstream music industry quite well. The reasons for this framing are twofold. First, the majority of the music produced within the mainstream industry is aimed toward audience members who are not cultural producers themselves. Secondly, the goal of the mainstream industry is to reach as large an audience as possible through its cultural goods (Bourdieu, 1993, p. 115). This is the field that is reflected in much of the data surrounding analyses of Canadian music, as its focus on economic capital lends itself more easily to quantitative study. According to Statistics Canada, in 2009 the Canadian music industry generated $\$ 858.9$ million in combined operating revenues, which largely reflects the economic leanings of heteronomous production (Sound Recording and Music Publishing Service Bulletin, 2009, p. 1). While the national industry did experience a $3.2 \%$ decline over the span of that year, its revenues are still significant.

As a component of that field, the types of support offered to artists are frequently engineered to bring about these economically-based types of success. However, this points to a disconnect between the ways in which cultural assistance is offered and the 
struggles faced by many independent musicians, particularly those working outside of mainstream genres. The differences in the ways they create art, both in terms of stylistic decisions and the values and practices they adopt, may render them misunderstood by policy institutions and other dominant cultural structures (van Veen, 2003, p. 14-15). Experimental artists tend to have differing attitudes from the mainstream with regard to the performance and sale of music, the ideal creative environment, and the values associated with varying types of cultural goods or actions. These fundamental differences set them apart from the traditional framing of artists within the field of large-scale cultural production, and what is especially problematic about this trend is the lack of awareness it has received from either policy or academic discourse. This limited access to resources can increase the struggles faced by certain experimental musicians in supporting themselves as artists as well as getting their works exposed to a greater audience, resulting from their decision to work in a style which is less popular with mainstream audiences.

What often goes unacknowledged are the differences between experimental artists and those who fall within the tastes embraced by mainstream populations in terms of how they produce their music, make their livings, and what they ultimately strive for as artists. To fully grasp this disconnect a historical overview of the dominant discourse surrounding Canadian musicians is necessary, including critical discussion of the models supported by cultural policy and the music industry. By analyzing the dominant frames and logics that construct the model of the artist within cultural discourse, it becomes 
apparent that the way artists obtain access to resources and how they are ultimately envisioned by these institutions are very specific and operate on a set of assumptions that are not valid for the entire population of Canadian musicians.

The construction of a particular creative archetype can have many implications for musicians if the vision is adopted by institutions that attempt to involve themselves in various elements of the creative process. In Canada, this can be clearly observed through the example of cultural policy due to its close ties to many aspects of the national music industry, including direct connections it may have with musicians. Ever since the 1960s, cultural policy has played a fairly significant role in the production of artistic goods within Canada due to a shift in the mindset regarding the creation of these works. Instead of being regarded simply as artifacts, they became acknowledged as products of specific cultural industries that could be shaped in ways that would increase our economic independence and, as a result, our autonomy as a nation (Dowler, 1996, p. 330). This led to the regulation of certain industries through various policy mechanisms in an attempt to both protect and encourage the cultural production that was already taking place in Canada (Crean, 2000, p. 202). However, for many years the sound recording industry remained at the periphery of these discussions and it was not until much later that it became seriously acknowledged by the government as a valid and large-scale element of national cultural production.

As noted earlier, the issue of content regulation for broadcasters has become the focus of much of the literature analyzing the evolution of the national music industry over the past several decades. Since 1971, radio stations have been required to play a specific 
amount of Canadian music -- initially a minimum of $30 \%$-- as a condition of their broadcasting license (Wright, 1991, p. 307) ${ }^{13}$. This regulation was introduced by the Canadian Radio-television and Telecommunications Commission (CRTC) as a method of combatting the perceived flood of foreign, particularly American, cultural content that was thought to be invading Canada and making it difficult for the nation's homegrown artists to compete for exposure through radio airplay. By reserving a certain amount of broadcast time for Canadian musicians, it was suggested that they would stand a better chance at gaining audience exposure while simultaneously contributing to a stronger, more cohesive national culture. However, the issue of content regulation has occasionally resulted in controversy and negative responses; for instance, certain technicalities in the ways that music is determined to be Canadian or not have been described as unfair and ineffective in the past (Straw, 2004, p. 278). In addition to this, radio stations have complained that there is a lack of Canadian recordings that meet their standard of broadcast quality (Straw, 2004, p. 279). The result of this phenomenon is that some radio stations tend to rely heavily on established popular Canadian songs in order to meet their required quota. While this technically does fulfill the CRTC's requirements, it essentially "violates the spirit of the law by shutting out new Canadian talent, or current projects, from radio exposure" (Papizzo, 1994, p. 134).

\footnotetext{
${ }^{13}$ In the case of radio, quotas for Cancon vary according to what kind of broadcasting license a station has and what type of music is being played. For campus, community, commercial, and native radio, the minimum weekly quota for Category 2 (Popular) music is $35 \%$, while the $\mathrm{CBC}$ and Radio Canada must play at least $50 \%$ of this category. Special Interest Music, or Category 3, ranges from a $10 \%$ Cancon minimum (in the case of commercial radio) up to $20 \%$ for the CBC and Radio Canada. See http://www.crtc.gc.ca/eng/cancon/r_cdn.htm for the CRTC's full outline of radio policy regarding Canadian music.
} 
The movement to foster cultural policy intensified in 1982 with the release of the Report of the Federal Cultural Policy Review Committee, co-chaired by Louis Applebaum and Jacques Hébert. The report drew new attention to the recording industry and, building on the ideas of the Canadian content quotas that had been introduced in the previous decade, provided insight towards the plight of Canadian musicians and the industry in general (Wagman, 2001, p. 49). While Applebaum and Hébert recognized the importance of previous initiatives, they argued that the measures in place were not sufficient in gaining the necessary exposure for artists and that further government support was necessary in order to achieve this. "If quality Canadian recordings are to be available in sufficient quantity and variety for AM and FM stations to play, and Canadians to enjoy, federal policy must also concern itself with production, distribution, and marketing issues" (Federal Cultural Policy Review Committee, cited in Wagman, p. 51). More specifically, the authors recommended an increase in federal assistance to Canadian-owned industry forces that would in turn strengthen distribution and marketing, raising the profile of Canadian artists in the process (Wagman, 2001, p. 51).

This suggestion to provide financial assistance for the national industry combined with the desire to produce more Canadian music that would allow radio stations to maintain their Cancon requirements were some of the key motivations behind the establishment of FACTOR in 1982. Formed by a collaboration of private media conglomerates and government organizations, it provides grants and loans for recording, video production, touring, and other industry activities (Wright, 1991, p. 307-308). The CRTC dictated that commercial broadcasters channel funds towards FACTOR grants, 
which were available through the recommendation of juries comprised of music business personnel (Spalding, 2008, p. 141-43). With its current annual budget of just over $\$ 15,000,000$, the foundation claims to provide significant support to the national music industry each year (FACTOR Annual Report 2010-2011, p. 8). While this has unarguably benefited many musicians over the years, FACTOR's support of certain aesthetic styles and its reliance on a panel made up primarily of mainstream industry workers has stirred some debate. For instance, according to Spalding (2008), "The musical genres most likely to meet with jurors' approval were those that conformed to the dominant radio formats of the time, since FACTOR's main objective was to increase the supply of Canadian music to commercial radio. Hence, country, pop, and rock predominated" (p. 143). For artists whose tastes and aspirations lay outside of the mainstream aesthetic realm, obtaining this type of support could prove challenging due to the fact that commercial radio appeal was the primary objective of the funds. In addition to this, "an artist whose goal is to maximize airplay and sales often has to downplay regional characteristics in order to do so" (Spalding, 2008, p. 145).

In addition to FACTOR, other national initiatives that were established to assist various elements of the music industry include the Canadian Independent Music Association (CIMA -- though originally known as CIRPA from its foundation in 1975 until recently), the Canadian Music Publishers Association (CMPA) in 1949, and the Society of Composers, Authors and Music Publishers of Canada (SOCAN) in 1989 (Nordicity Group, 1995, p. 56). Of these groups, SOCAN tends to be the one that is most widely-known by artists and industry workers. Its role is to collect tariffs from a variety 
of spaces in which music is broadcast, such as venues and radio stations, which will in turn compensate artists whose copyrighted music is performed in public, including by means of telecommunication (Sanderson, 1985, p. 52). In 2005, $\$ 157.6$ million was distributed to members and international affiliates and this number indicates a steady increase from previous years (Canadian Heritage, pg. 15).

The Canadian recording industry has faced a number of challenges over the years which have resulted in a somewhat tumultuous status. According to Straw (2000), the English-language sector of the industry has traditionally suffered from a significant amount of fragmentation, which has led the industry to be "regularly buffeted by shifts in the degree to which multinational firms are interested and involved in Canadian musical culture" (p. 178-79). A lack of strong Canadian music distributors has led many labels to strike deals with large international corporations, such as Warner or Sony, instead of keeping their earnings contained within the national industry (Straw, 2000, p. 179). On top of this, during the 1990s many Canadian artists reached mass popularity and fled their national labels in favor of signing directly with major American companies (Straw, 2000, p. 180). A study co-chaired by the Canadian Recording Industry Association (CRIA) and the Canadian Independent Record Production Association (CIRPA) claimed that the domestic market was not large or strong enough to generate the sales and financial gain that are available to those who are active in international markets (Nordicity Group Ltd., 1995$, p. 2$)^{14}$. However, it is worth bearing in mind that a study spearheaded by federal

\footnotetext{
${ }^{14}$ It is worth considering that any study spearheaded by federal cultural institutions may follow the national trend of defaulting to discussions of cultural policy, and it is important to remain critically aware of this tendency. See Wagman's 2010 paper “On the Policy Reflex in Canadian Communication Studies."
} 
cultural institutions may present an inherent bias within its portrayal of the industry and thus demands an increased level of critical awareness.

Although the dominant discourse frames the Canadian music industry as considerably weaker than its American counterpart ${ }^{15}$, it is also quick to point out the mainstream popularity of many of our country's artists. In 2005 , an increase of $11.6 \%$ in performing rights royalties indicated a significant jump in the amount of exposure received through broadcast and other media, while large percentages of the national population have claimed that they listen to Canadian music on a regular basis and consider its quality to be on par with or above that of international artists (The Canadian music industry 2006 economic profile p. 3; p. 13-14). However, not all types of music have experienced this rise in popularity equally. As a general rule, the industry as a whole is geared towards specific aesthetics with defining trademarks or characteristics. The overall focus of the mainstream industry tends to place its focus on singles in certain genres as a result of the overarching social and economic conditions of popular music production. Grenier (1990) suggests that "within this new socio-economic mode of organization of music, songs are considered to be discrete, relatively homogenous (3-5 minute pop song)" units which stand on their own as the building blocks of larger industrial mechanisms, such as radio play and television placements (p. 217). A resulting consequence of this is that the music business as a whole has the tendency to marginalize or ignore certain types of music that do not fit into these aesthetic guidelines, which in

\footnotetext{
${ }^{15}$ Statistics back up this claim. The American music industry earned a net value from physical and digital music sales of \$6,850,100,000 in 2010 (Recording Industry Association of America 2010 Year-End Shipment Statistics) while Statistics Canada's report "Sound Recording and Music Publishing" demonstrates that the Canadian industry generated $\$ 380,459,000$ in the sale of musical recordings in 2009 (14).
} 
turn can make it difficult for more experimental artists to claim legitimacy from dominant social or cultural institutions. Artists who stray from mainstream styles tend to work almost exclusively with smaller business firms because the lower costs and expenses of these companies allow them to take greater risks in partnering with artists who have either chosen to avoid or have not yet developed large-scale popularity as a result of their music (Straw \& Berland, 1995, p. 340).

These criticisms of the industry stem from the traditional economic-based perspective that financial gain is always the primary goal of the artist. The challenges faced by non-mainstream artists are often quite different from those experienced by musicians who fall within widely accepted mainstream tastes, and because institutions that are meant to help support artists may not fully grasp what it is to be working within a smaller field of production, these policy bodies might fail to offer adequate or appropriate assistance. Since the overall understanding of the artist within the dominant discourse is shaped by a combination of cultural policy and music industry perspectives, artists who do not fall within the traditional framings supported by these bodies risk being misunderstood on a larger level as well.

According to the literature about musicians and how they support themselves, there are several different ways in which they typically earn a living. In The Music Industries in Canada, Will Straw and Jody Berland (1995) claims that income can be obtained through live performance, publishing and mechanical rights, record sales, and the creation of commercial jingles (p. 153). The degree to which each of these avenues is used depends on the style of music being produced, the artists' values and goals, and the 
business opportunities and knowledge they possess, among other factors. The same can be said for record labels which utilize these methods via their artists. Rowland Lorimer and Mike Gasher (2004) use the independent label Battle Axe Records as an example, explaining that the label has promoted the hip hop group Swollen Members through releasing albums on vinyl, consistent touring, and targeted merchandising and branding of apparel that is linked to the artists (p. 170). This example of specific merchandising, particularly the production and sale of vinyl, is more common in styles of music that do not fall under the umbrella of mainstream pop, rock, or country. What these accounts assume, however, is that artists are able to survive largely off their creative work. The validity this assumption has for artists working outside of the mainstream is not addressed, and this raises the question: to what extent are these artists able to sustain themselves financially on their creative endeavors?

If we are to talk about musicians as an inclusive category or the music industry as a whole, it is essential to look beyond those who work in the field of large-scale production and also recognize those whose work, regardless of its genre, circulates through more restricted fields. The components of the large-scale field of production -- in this case, the mainstream music industry -- consist of commercial radio airplay, distribution, government grants, studio recordings, large-scale touring, and a number of other elements. In other words, these are the practices that structure much of the activity for mainstream artists. While some of these factors overlap with the structures that make up fields of restricted production, including experimental music scenes, the activities of artists tend to be quite different in these smaller fields. The assumption that the elements 
of the mainstream field apply to all Canadian artists is not a valid one, and it is through this assumption that artists working within restricted fields may be excluded from the overall frame of Canadian music knowledge. Through the inclusion and understanding of these artists' experiences, we add depth and complexity to the understanding of how music works in Canada. 


\section{Chapter 3}

\section{Analysis of the Field of Restricted Production}

If we are to develop a better understanding of how artists function within scenes and remedy the lack of their first-hand voices within cultural frameworks, the best way to approach this scenario is to reach out directly to these creators and listen to their stories. By doing this, it will allow for a more complete vision of their lived realities that will, in turn, expand the current understanding of the artist within the logic of the industry.

Bourdieu's fields of cultural production help to place the experiences of the artists interviewed in this study in a way that recognizes the varying types of capital they may encompass. The artists I interviewed participate almost exclusively in the field of restricted production, which is evident from both the scale on which they operate in terms of selling their products and also the values that they uphold and types of capital they most strongly embrace. In order to fully demonstrate how these artists exemplify the different facets of Bourdieu's model, we can analyze a number of different elements which comprise the field and discuss how these musicians negotiate the tensions surrounding the accumulation of various types of capital. Based on the interviews, I was able to identify some of the key components of the scenes they inhabit. Community, physical space, time, recorded albums, and touring all contribute to the experiences of artists within various scenes. By analyzing the interview data through these frames, I was able to develop an understanding of the complex realities of experimental music scenes.

One of the most striking trends that indicates a preference toward small-scale production was the notable lack of discussion focusing on economic gain. While money 
was brought up on a number of occasions -- most often simply in the context of not wanting to lose any through the production of their creative work -- the majority of participants were more focused on creating and sharing their work than accumulating any significant earnings from it. None of the participants supported themselves solely through their musical practices. Similarly, when discussing the challenges that were most pressing within their creative process, the subject of economics rarely entered the picture. In the field of restricted production, cultural and social gains are typically prioritized over an increase in financial capital. Through the mapping of the activities and issues that comprise a scene, these priorities emerged as defining elements that shape the ways these artists function.

\section{Community}

Building on Bourdieu's notion of social capital, many of my participants identified the development of a sense of community and interpersonal support as one of the primary components of their scene. One of the distinguishing features of the field of restricted production, which can also be observed in Straw's concept of the scene, is the constant effort put towards fostering social connections through particular activities (Straw, 2004, p. 412). Bourdieu (1993) states that within the restricted field, the audience is often made up of other creators and based on the findings from my interviews this was generally the case (p. 115). The individuals populating an audience are often other musicians, but they may also be label owners, concert promoters, recording engineers, designers, photographers, or any other number of roles that contribute to the makeup of a 
scene. It is fairly rare to find someone in attendance at an experimental music concert who does not, in one way or another, directly contribute to the field which encompasses that event. As a result, scenes can become very tight-knit and supportive, and the sense of community that often emerges from this is of great importance to artists. The feeling of membership that scene members gain from this leads to an increased level of social capital, which can then result in either material profits (like the services that may become available upon joining a group) or symbolic profits (for instance, an elevated reputation due to association with a prestigious group) (Bourdieu, 1986, p. 52). From a number of different interviews, I got the sense that the social ties within a scene are one of its most valued elements, yet they also can become the focus of concern if they are thought to be weak.

A common complaint about the music scene in Ottawa is the fact that artists and other contributors frequently leave for the larger urban centers of Montreal and Toronto. The strong sense of social connection typically fostered in music scenes, particularly those focused around experimental styles, helps to explain why some musicians feel so strongly about the other members of their scene. For them, the social capital supersedes other types of gain and thus the interactions and contributions of all members of the community are considered important. In turn, this results in the feeling of jeopardy caused by the exodus of artists and other scene participants for larger urban centers. Brian, who has a long history of creating and promoting culture within the Ottawa area, explained that he struggled with the discouragement that results from individuals moving to other cities without making the effort to contribute or give back to the creative 
community which had initially fostered them. For him, that weakening of social ties can potentially jeopardize the local support system that exists for artists:

You could go to Montreal and be part of a really big music scene that's built on the goodwill and hard work of other people, and you can take advantage of that and not have to be the person that makes it ... People are either going to step up and do the work and take care of each other, or they're going to move somewhere else. And most people move somewhere else (Brian, personal interview, Oct. 13 2011).

Chris also commented on this trend, becoming visibly frustrated when stating that:

[When] musicians don't feel like there's an aesthetic or a community where their music is appreciated or they have opportunities ... a lot of them will leave to find those opportunities in other places where they have the infrastructure. So you have the media attention, or a bigger audience, and you have more places to play, or more opportunities to try to eke out a living (Chris, personal interview, Oct. 3 2011).

Because social connections and urban surroundings play a key role in structuring music scenes, these levels of opportunity can have significant impacts on the ways artists live. The availability of certain resources within a scene can provide either encouragement or discouragement for the creation of music, as described by Geoff Stahl (2001):

Access and the ability to mobilize local and non-local support and resources depends on the degree to which economic, political and social forces impinge on local circumstance, which in turn may determine both the desire and ability to get beyond it (p. 110).

This account of the elements within a scene match up with many of the participants' experiences. The connections between specific urban or geographical areas and scenes are, in many regards, defined by the tensions identified by Stahl. Straw (2001) suggests that "scenes extend the spatialization of city cultures through the grafting of tastes or affinities to physical locations," which further reinforces the notion that the urban spaces containing scenes can impact the ways in which they function, or vice versa (p. 254). 
The feeling of connection to a particular urban space, both geographically and socially, tends to be very important for artists since it generally signals a sense of belonging within that area's musical scene. It is this perception of inclusion that can help to strengthen the overall musical culture of which scene members see themselves as part. Additionally, it also demonstrates the highly localized nature of experimental music scenes which stands in stark contrast to the vision of a larger, national scene that is so prevalent within literature surrounding the mainstream industry. Straw and Sutherland (2007) state that "music remains, particularly for young people, an important tool by which identities are given shape and meaning, or through which people develop a relationship to the times and places in which they live" (p. 157). Thus, the opportunities (or disadvantages) tied to various social or spatial capacities within a scene have the ability to impact artists on an individual level as well as the greater cultural arena they work in. In some cases, this can lead to a cohesion of musical practices or aesthetics specifically tied to a geographic area that can be recognized both by those within its scene as well as external observers ${ }^{16}$.

Building on this notion of social connection and interaction, the ability to collaborate artistically with other members of a community is another practice within the field that is considered highly valuable. Jennifer, who works primarily with synthesizers and reel-to-reel tape in a variety of electronic projects, cited the ability to collaborate on projects with artists from other geographic areas or creative fields as a particularly useful practice as it can lead to both social and artistic gains. She explained that her ideal type

${ }^{16}$ Straw uses the example of Montreal's St. Laurent scene in the articles "Cultural Scenes" and "Scenes and Sensibilities." 
cultural support would "[facilitate] cross-collaboration and crossing of genres and crossing of boundaries" (Jennifer, personal interview, Oct. 8 2011). Mike, who composes solo piano pieces as well as electronic works using no-input mixers, also shared Jennifer's appreciation for the ability to share creative ideas through collaboration. He emphasized the value in being able to work outside of the restrictions imposed by one's home province or country: "[Art] is helping communities and cultures communicate with each other, and music does that on such a big level. So what's the point of making music if you're not going to communicate with people, and what better way to communicate with people than on an international level?" (Mike, personal interview, Oct. 2 2011). What is worth noting about these last two quotes is that both are from musicians who have performed internationally, and obviously found the experience to be worthwhile. Mike claimed to have lost "lots" of money in the performance of his music, yet ultimately the cultural capital gained from sharing his work with audiences abroad proved more beneficial than any financial losses that came as a result of the travel activities.

The sharing of creative works with an audience as well as the opportunity to impart one's technical or artistic talents to a group of peers in the form of skill-sharing was cited as an important benefit for many of the participants. Not only does this practice serve to establish a new set of creative abilities within a field that can be used to produce an even broader spectrum of works, it also builds social connections between the producers and consumers of cultural goods, ultimately reinforcing Bourdieu's claim that the audience is primarily composed of other creators and participants within the field of restricted production. Additionally, it demonstrates how material resources can be 
accumulated and shared as a result of the social capital one gains through membership in a group (Bourdieu, 1986, p. 52). Jennifer stated that the process of collaborating with fellow artists is often the most challenging aspect of creating work; however, when she makes a successful creative connection with another artists, the experience can also be highly rewarding. She described "all the energy that comes with being a creative person and working closely with others" combined with her own internal artistic motivations as the key reason behind her production of music (Jennifer, personal interview, Oct. 8 2011).

The sense of autonomy derived from this creative motivation coupled with the distinct lack of any economic discussion within the description of her practices as an artist provides a stark contrast with the image of the musician propagated by many larger institutions. There is no desire for tour buses or mass record sales; instead, there is the simple act of producing a creative work through collaboration. The primary motivations behind the musical activities for many of the participants consisted of the joy derived from the creative process itself and being able to share that process with others, either through collaboration or by performing the works for an audience. Jennifer explained that she has minimal economic aspirations tied to her music and instead she is "more interested in community-building and supporting pals and ... making interesting stuff and helping each other out. It would be cool to make money doing this, but I don't feel driven in that way. It's not about that to me" (Jennifer, personal interview, Oct. 82011 ). This quote is typical in that it contains sentiments expressing the value of social and cultural capital shared by several of the participants while simultaneously downplaying the 
importance of any financial capital that could result from the production of musical works.

The example of collaboration and its value to the artists who engage in it can also be seen mirrored in the greater interaction between a single musician or group and the other artists within their community, regardless of whether or not they work on a joint project. The development of cultural and social capital is a key element within musical scenes, and it is recognized by both producers and consumers of non-mainstream music as a vital positive force that can be highly beneficial in the sustainability of a small-scale field. Through the process of accumulating social capital, artists are able to share in material profits (for instance, through services produced by social relationships) as well as symbolic profits (such as the association with a prestigious group of artists) (Bourdieu, 1986, pg. 52). Brian described his motivation behind writing and performing music: "You're doing things for your community and the people you love and for the people that enabled you to do it in the first place" (Brian, personal interview, Oct. 13 2011). The desire to give back to one's community or contribute to emerging or established cultural trends fostered by a particular scene was an idea shared by other participants as well. The benefits of being a member of a healthy music scene can lead to a shared sense of purpose and the notion of working towards a common goal, as Paul explained. He elaborated on this thought by describing how members of his creative community actively try to support one another through various avenues of promotion and how, through their combined efforts, they have managed to establish a more cohesive scene and increase the exposure of the artists working within it (Paul, personal interview, Oct. 3 
2011). This can take place through the organization of concerts, assistance with recording, or any other number of activities that contribute to a musical scene. Ultimately, it has the effect of contributing to the development of social capital as well as leading to an increase in cultural capital due to the encouragement of increased production from other members of the scene.

What this may risk, in some cases, is the conscious or unconscious formation of boundaries at the perimeters of a music scene. The tight-knit nature of certain scenes may contribute to a perception of exclusive membership, which could discourage outsiders from engaging with or making efforts to understand the activities of the scene's members. While all of the artists who referred to the sense of social capital within their scene talked in a manner that suggested a consciously inclusive attitude among the scene's contributors, there is nonetheless a risk of developing a reputation of being cliquey or elite when participating in tightly-connected cultural fields, especially those which are small in size. None of the participants brought up this negative result of scene activity, in all likelihood because they observe scenes from the inside and thus identify as contributors. Those outside the field, however, lack the sense of social connection as well as possibly missing the cultural capital necessary to unlock the symbolic capital engrained in many of the scene's cultural products and activities.

While most of the discussion surrounding musical collaboration and the sharing of ideas focused on exchanges that happen on an informal level, this practice can also take place in a more structured manner. One of the most positive accounts of cultural 
grant support was described by Jennifer in her discussion of the Jeunes Volontaires program run by Emploi Québec. Part of the reason why she found it so valuable was because it allows young artists to work with a mentor of their choosing (Jennifer, personal interview, Oct. 8 2011). This mentor is an individual considered to be knowledgeable within that particular field and he or she acts as a guide throughout the course of the program, overseeing a project's creation and acting as a liaison between the artist and the institution. This arrangement helps to mitigate some of the tensions expressed by artists towards the bureaucratic nature of policy agencies as well as building social capital between the mentor and the artist. Those who had been directly involved with the program claimed that they found it easier to deal with another artist who had a better understanding of their struggles and goals as opposed to trying to communicate with policy workers who only had experience with the industrial side of cultural production (Jennifer, personal interview, Oct. 8 2011; Nick, personal interview, Oct. 14 2011). Since the mentor is generally another artist from the same scene, he or she will likely have a much deeper understanding of the realities faced by applicants and what challenges they face. Additionally, participating in the same scene may allow the applicant to be more open with the mentor about struggles he or she may be having. Jennifer, who had received a grant through this program several years ago, went on to describe how she is currently acting as a mentor for another member of her scene who is engaging with the program for the production of his own music (Jennifer, personal interview, Oct. 8 2011). In this sense, the model is cyclical and seems to foster greater levels of the types of capital deemed most valuable by artists due to its collaborative 
nature and its lack of emphasis on the commercial appeal of any work produced. The participants who spoke of Jeunes Volontaires described it in ways that made it seem more geared towards developing skills and giving opportunities to youth as opposed to specifically funding projects with a defined cultural or commercial goal in mind (Jennifer, personal interview, Oct. 8 2011; Nick, personal interview, Oct. 142011 ; Ashley, personal interview, Oct. 14 2011). This perception of a combined focus on the accumulation of knowledge or competence and the increase of social connections within a community make it more appealing to artists due to fact that the goals of the program seem much more in line with the artists' own goals than much of the other existing music policy.

Ashley, who had never been directly involved with Jeunes Volontaires due to her age (individuals must be under 30 to apply) but has seen many other members of her scene take part in it also described its structure in a favorable manner: "It allows you to work with your peers. Your mentor is often somebody that is within your milieu or is a friend of a friend, and it makes for more of a human contact" (Ashley, personal interview, Oct. 14 2011). In addition to benefiting young artists by allowing them to work with an individual they view as more of an equal, she explained that the act of being a mentor can help artists as well through the development of knowledge as well as the contribution it makes to their professional résumé. This understanding of not only the financial challenges that artists can face but also the recognition of social capital made this agency unique in its almost entirely positive description from the participants I interviewed. 
The more collaboration-based practices used by the Jeunes Volontaires program can be contrasted with the typically bureaucratic nature of most cultural policy organizations, and this tends to make these agencies targets of frustration for artists. Some participants explained that they felt the granting bodies focused too heavily on process and paperwork and not enough on the needs of artists and communication. Free jazz saxophonist James suggested that the bureaucratic structure of granting agencies renders them unable to "respond quickly enough to changes in the musical world to support them in a timely way" (James, personal interview, Oct. 2 2011). From his perspective, the abundance of regulations and documents slowed the evaluation process to the point where many organizations were no longer able to maintain awareness of new directions in musical innovation.

Several participants complained that they felt misunderstood by larger institutions, including policy bodies, based on certain choices made or creative practices they had adopted (Nick, personal interview, Oct. 14 2011; Ashley, personal interview, Oct. 14 2011; Rebecca, personal interview, Oct. 4 2011). Given that most of my participants focused their energies towards building community and expressing themselves through new artistic forms, they found themselves at odds with what they perceived to be overly formal, complicated, and occasionally profit-driven cultural initiatives. Chris described his perception of cultural support bodies as a bureaucratic process that demands "a highly specialized sort of knowledge about the presentation you need to make to get a grant." He concluded this thought by stating that artists who do not come from a bureaucratic background or do not have experience working with those 
types of processes can be highly discouraged by this experience: "They either don't feel like they can go through with that process or ... it doesn't seem accessible to them" (Chris, personal interview, Oct. 3 2011). Brian offered similar sentiments by stating that the structure and values of Canadian arts policy organizations limit the creativity that can take place through the exclusion or ignorance expressed towards of certain types of content. He argued that this structure can ultimately be detrimental for some creative fields:

If [arts organizations] continue to fund bureaucratically, then they're actually doing more damage than good. Because the message that they're sending, whether they like it or not, is 'there are certain things we won't promote.' And that sucks, because there's so much music that is not going to get made because people don't feel encouraged to do it (Brian, personal interview, Oct. 13 2011).

Elaborating on this thought, he explained that in addition to the attitude of certain policy bodies that can potentially limit creativity, the language they use to communicate can be isolating for artists as it strives to become more in line with that used by dominant political and economic forces. "Their stand is always taking on the jargon of administrators and government and talking back to them in their language and it just becomes the language of that institution ultimately. And their mandates start to look like legalese jargon" (Brian, personal interview, Oct. 13 2011). Since few artists have a background that would allow them to understand and critically negotiate this process, he suggested that its ultimate result is the limiting of creative activity within scenes at the hands of the very institutions. which claim to provide the most support for Canadian musicians. In a similar critique regarding the tendency for music policy to hinder new developments in musical creativity, James described his observations regarding perceived 
favoritism within granting agencies for genres that are highly established within institutional discourse, such as classical music. This troubled him because, in his opinion, it had the effect of restricting the resources that would then be available to artists working in more adventurous styles (James, personal interview, Oct. 2 2011).

For artists working in these experimental genres the ability to learn from other members in one's scene remains important regardless of its status as an institutional or casual process. Once an artist has had some level of experience or success within the production of music, there is often a sense of wanting to give back to the community that provided the initial support for his or her creative work. This generally occurs in the form of assisting younger artists with the production of their own music, be it in the form of help with recording or organizing shows or simply offering critical feedback and social support. Some participants believe that once an artist has reached a certain level of success as an act or has developed a strong sense of knowledge about the process of cultural production, he or she has a certain amount of responsibility tied to the action of giving back to the original community (Rebecca, personal interview, Oct. 4 2011; Brian, personal interview, Oct. 13 2011). This form of assistance allows the scene to maintain its sense of autonomy since the help is being given in a way that does not impact the way that its products are judged. Additionally, it can help to strengthen interpersonal ties and thus contribute to the scene's degree of social capital.

Responsibility aside, many successful artists simply do this out of a desire to use the knowledge accumulated through their experiences as a means of contributing to the activity of a scene. One particular example of this which was brought up by multiple 
artists was that of Montreal's Godspeed You! Black Emperor. After the band had reached a significant level of success, its members went on to contribute heavily to the Montreal scene through their activity in the running of venues, particularly Casa del Popolo, as well as assisting with Constellation Records, the label that had released much of the band's material over the years. The label shares the group's sentiments regarding the importance of social capital and a sense of wariness towards the way that major record labels and other economic-driven entities function within the mainstream music industry, which results in a high levels of autonomy and symbolic capital. In addition to this, the venues with which they have been involved are frequently cited as key spaces within the landscape of Montreal due to their acceptance of most musical styles and their level of accessibility for emerging artists ${ }^{17}$.

Support between artists can also take place in the process of recording and releasing material. Mike described the assistance he received from a former band-mate in the manufacturing and release of his albums, which allowed him to create a larger run of material while simultaneously strengthening the social capital within their scene (Mike, personal interview, Oct 2 2011). Much of the DIY mindset still remains because all of the work is being accomplished within the artist's immediate scene, yet the sense of helping with the overall process of releasing an album allows other members of the community to share in any sense of accomplishment which results from its completion. Paul, who happens to be the co-founder of a small record label in addition to playing a variety of instruments in both popular and experimental electro-acoustic projects, claims that the

\footnotetext{
${ }^{17}$ See Geoff Stahl's article "Tracing out an Anglo-Bohemia: Musicmaking and Myth in Montréal" in the journal Public 22-23 (2001) for a more detailed account of this particular scene.
} 
motivation for starting the label simply came from observing of all the creative production that was happening around him and wanting to give those musicians a greater opportunity to be heard. "There was a lot of stuff happening amongst friends ... there was a lot of creative flow going on -- not putting out records, but making music" (Paul, personal interview, Oct. 3 2011). In this sense, his label serves the purpose of harnessing the cultural capital circulating loosely within a scene and giving artists the opportunity to be part of a more structured process without jeopardizing their sense of autonomy. He says that the label does not promise any money to artists because, like the musicians themselves, the individuals behind the label are not producing cultural goods in hopes of achieving financial gain. Instead, the label helped to establish a more cohesive reputation for the scene as a whole, thus leading to greater recognition from those outside of its home area. Chris, who is part of that particular scene but not directly involved in running the label, demonstrated this phenomenon when he mentioned playing with an out-of-town band that commented on the connection between the label's overall sonic aesthetics and its ties to a particular geographical scene: “"It's got that Hull sound"' (Chris, personal interview, Oct. 3 2011). Chris expressed how excited he was to hear a band from a different city recognize both the particular musical traits and the strong awareness of community present in the label. This example points to the importance of cultural and social capital within the running of a small independent label and how these values are recognized and appreciated by artists inside and outside of that particular scene.

This DIY ethos to which several of the participants referred may signal a dual role as an indication of symbolic capital within a scene as well as a defense mechanism 
against the greater forces of the large-scale field. The actions of recording, manufacturing, and promoting one's release singlehandedly or with the help of a small group of peers disrupts many of the traditional processes that constitute the music industry on a large scale. Through rejecting the use of major recording studios and other institutions that are normally seen as necessary for success, these artists also distance themselves from the goals that are associated with mainstream popularity. This can serve to protect the artists from the lack of economic capital that may be derived from their work which, for many experimental artists, is a common experience due to the restricted size of their market or field. By placing the emphasis instead on different types of capital, artists shield themselves against the traditional notions of success and failure as they are generally framed within the larger industry.

\section{Space}

Another common concern that was raised by interviewees in pursuing their craft was the issue of finding space in which to work, either for the creation or the exhibition of their work. For artists working outside of established aesthetic traditions, finding venues that are willing to accommodate their music can be difficult. Ashley, who works largely with sonic installation art, including a mix of field recordings and the use of found or modified objects, described the lack of galleries that are willing to host her kind of material (Ashley, personal interview, Oct. 14 2011). She explained how the ones that are accepting of the aesthetics she works with focus almost exclusively on showcasing the work of more established artists from the field. As a result, she struggled extensively to 
simply find spaces that were not only open to her chosen genre but also willing to exhibit works from new artists. She described this process as being "extensively discouraging" -especially given that she struggled to get feedback on her proposals from the galleries she was applying to. This lack of feedback made it challenging to improve her subsequent applications because she was unclear of how to specifically go about fixing any weaknesses within her proposals.

Other artists also expressed the need for sustainable venues within their community. Musicians involved in genres ranging from abstract electronics to avantgarde string compositions explained that there is a widespread need for places in which they and their peers can perform their music regardless of the commercial appeal of their particular style. According to Chris,

There needs to be affordable places for artists to play. It feels like at least in Ottawa and I know in Vancouver there's a lot of struggle around having a stable, accessible, open space where people can perform music. Especially music that's a bit stranger so it's not going to draw as many people as the mainstream stuff (Chris, personal interview, Oct. 3 2011).

He followed that statement with recollections of his experiences playing in bars performing abstract electronics, electro-acoustic, and noise -- a scenario in which the bar owner typically would not allow the artists to come back due to the devoted but small crowd they would draw.

This further demonstrates the tensions that can arise between those who strive to produce autonomous work in an industry that is largely driven by economic forces. Many of the participants described the challenge of finding venues that are accommodating to musicians who aim primarily for cultural or social capital instead of financial gain; venue 
owners, open-minded as they may be, are still running a business and have their own financial responsibilities to take care of. Brian suggested that this is an area in which policy support could be particularly useful. When asked what the most valuable type of cultural support for him as an artist would be, he claimed that for him, "the best support could be an open space to be able to present the work that is not requiring us to make a lot of money for that space" (Brian, personal interview, Oct 13 2011). Musicians working in non-mainstream genres are, quite often, content with simply performing their music without any significant financial gain as payment, but finding venues that share an appreciation of cultural and social contributions in lieu of mass economic gain is a more challenging feat. Elaborating on this thought, Brian argued that this challenge is especially crucial in Ottawa given its adherence to established economic and political traditions and its high cost of living:

This city's organized around economic models and political models that have no care for any of that stuff, so it's hard to stand up in the face of the government culture here and say, 'I'm going to start a venue here that doesn't have to make any money, and somehow I'm still going to pay my rent in one of the most expensive cities in Canada' (Brian, personal interview, Oct. 13 2011).

The challenge of finding accepting venues often leads musicians to perform in spaces that are aesthetically open but frequently non-sustainable: basements in Ottawa, industrial lofts in Montreal, parking lots in Vancouver. These areas are generally not run for profit and instead aim to foster creative innovation and a sense of community. However, because they are typically coordinated by a loose collective of people volunteering their time and energies, they seldom function as long-term resources for artists who wish to perform within the space. A number of examples of these spaces were brought up during 
the course of interviews, such as Montreal's La Brique and The Pines and Ottawa's 5 Arlington. These spaces can vary in terms of their legality, and the anarchistic attitudes embodied by some of these spaces may also to contribute to their short lifespan as viable creative spaces. As a result, many artists expressed the desire for safe, welcoming areas that possessed the same open attitude as these unofficial venues, yet had a more sustainable model that could lead to a stable, long-term existence. In addition to providing spaces for local musicians to perform their work, Chris suggested that their existence within the local scene would allow greater opportunities for touring musicians to play in his city and thus form ties between different creative communities based on shared experiences and the exchange of ideas (Chris, personal interview, Oct. 3 2011). In Montréal, the venue situation is somewhat more favorable than in Ottawa. There are a small number of established venues that make significant contributions to the local music scene -- particularly the Casa del Popolo and its larger counterpart, Sala Rossa. Jennifer, who has lived in Montreal for several years and has played at both venues, explained the role of these particular cultural spaces: "Montréal's lucky to have Casa and Sala. I think the Casa's pretty special ... it's so wide open and so, in my experience, very hospitable to difference, aesthetically and otherwise" (Jennifer, personal interview, Oct. 8 2011). Since its establishment in 2000, Casa del Popolo (generally shortened to simply "Casa") has become a hub for much of Montréal's music and arts scene. As the frequent host of shows spanning a variety of genres in addition to being one of the key sites of the annual Suoni Per Il Popolo festival, this St. Laurent bar is an 
important venue for both experimental artists and members of other scenes throughout the city ${ }^{18}$. Casa's open-mindedness towards more experimental types of music and its history as an institution with strong community ties has led it to foster types of capital not solely rooted in economics, which is somewhat rare for a legitimate (in other words, officially licensed and legal) venue. In this sense, it contributes to the social capital as well as the symbolic and cultural values circulating within a scene by providing a space in which various interactions can take place between artists and other members of the field of restricted production. This sense of fostering multiple types of capital, including those which tend to be of the most personal significance to artists, is a strong indication of why it was so highly praised by Jennifer and the other artists who discussed its role in the local scene.

Spaces like Casa del Popolo provide a more stable alternative to the constant fluctuation of the city's lofts, which may serve as important venues yet typically lack the sustainability offered by a more established and respected performance arena. Despite this, lofts and other industrial spaces play an important role in addressing the need for accepting venues that several of my participants (particularly those based outside of Montréal) had expressed (Chris, personal interview, Oct. 3 2011; Brian, personal interview, Oct. 13 2011; Paul, personal interview, Oct. 3 2011). Montréal, with its history of cheap rent and significant amount of converted industrial space, facilitates types of creative experimentation that are considerably less frequent in other cities. A contrasting example: the lack of raw industrial buildings in Ottawa and its decidedly more residential

\footnotetext{
${ }^{18} \mathrm{See}$ http://www.casadelpopolo.com/contents/casadelpopoloAbout for more information about the venue and a selected list of the artists who have played there.
} 
landscape results in a significant number of musicians renting out houses with basements where they can practice or hold shows; however, in these cases, artists are then subject to residential noise bylaws and the tolerance of neighbors.

The issue of space is also evident in the struggles that some musicians face in terms of finding an area to craft their work. For many of the participants, the creative process takes place largely within their homes -- this is the primary site of writing, recording, and producing their material. This practice seems to be most frequent amongst electronic musicians, largely due to the ability to plug in headphones and isolate much of the noise that may disrupt roommates or neighbors. Other musicians who work with sonic styles less easily contained cited practice space as an element that is sometimes difficult to find. When asked about his biggest struggles and how policy initiatives could help remedy them, Paul claimed that the most valuable type of cultural support that could be offered to his band would be an accessible space, preferably in an industrial area (residential noise bylaws are hurdles that musicians often have to negotiate carefully) where they could practice and record freely. He explained that money is not an issue for him and his collaborators; they are willing to pay for the space, but it is simply not available in their community (Paul, personal interview, Oct. 3 2011). Other interviewees had more success in finding space to rent for jamming, although these rooms can vary in terms of overall quality. One now-defunct jam space in the basement of a Montreal commercial building was described by Jennifer, who used it for several years, as "disgusting" but also "cheap and very conveniently located" (Jennifer, personal interview, Oct. 8 2011). The space was shared by a rotating cast of artists who called it 
the Swamp due to its distinct and infamous odor. In a city like Montreal where residential basements are rare, this scenario of a shared rental space in a commercial or industrial building is fairly common. Based on the artist's location and the financial resources available, space in which to create his or her material may either be very easy to establish or could potentially be a significant hurdle within the big picture of an artist's creative process.

\section{Time}

The issue of time and the struggle to balance all of the different tasks in life was one of the difficulties noted by several participants. Most of the interviewees worked fulltime, some more than full-time between multiple jobs and educational pursuits. This allowed several of the artists to fund their musical endeavors out of their own pockets and some of these participants were very vocal about wanting to keep it that way. None of the artists I talked to earned enough financial capital from their music to fully support themselves; each participant had at least one job, although some of these were part-time and temporary to accommodate touring. In order to maintain a sense of creative control and responsibility, Rebecca suggested that it was beneficial to create a "sustainable business model for yourself as a band," indicating the value she saw in remaining as economically autonomous as possible in the production of art (Rebecca, personal interview, Oct. 14 2011).

Some of the musicians interviewed had applied for various forms of grant support in the past with mixed results ${ }^{19}$. The motivation behind this action was typically a desire

\footnotetext{
${ }^{19}$ Examples of participants who were successful in getting cultural funding: Chris had received a City of Ottawa grant for recording, Jennifer's band released an LP as part of the Jeunes Volontaires program,
} 
to cut down on the hours spent at one's job and thus increase the amount of time that could be devoted to the production of art. However, previous struggles with the grant system may have led to an increased desire to take the DIY route due to the unreliable nature of receiving government-based cultural support. This may be a partially jaded response to past failed applications, or else it is simply the recognition that a grant application may or may not be successful and thus should not be counted on as a guaranteed form of support, despite the way that cultural organizations may frame their accessibility. Brian recounted his experience applying for grants as a member of a multiinstrumental electro-acoustic group: "I applied to FACTOR eleven times between 1986 and 1989 and I was turned down every single time ... I've applied to the Canada Council four times and been turned down each time." What was especially striking about this example is that after so many unsuccessful grant applications, the Canada Council contacted him and asked him to participate in their jury process. After these failed grant attempts, he described how he "found it odd that they would then call and say, 'We're not going to give you any money, but we'd like you to come and judge whether we give other people money"' (Brian, personal interview, Oct. 13 2011). This lack of government support seemed to contribute to feelings of cynicism among the participants towards particular granting agencies, and often reinforced their adherence towards DIY attitudes. However, while this type of experience may strengthen any moral or political attitudes involved with the creation of music, it can also restrict the amount of time that artists are able to spend on their music due to the need to support themselves financially. allow them to tour. Brian, Ashley, Jennifer, Robert, and Rebecca all described unsuccessful attempts to gain funding in their history as artists. 
In a further discussion about how a lack of time impacts the creation of art, Rebecca, who combines drone music and classical violin in her various projects, suggested that "it's all about having the time, and I think people want to link having money and having time" (Rebecca, personal interview, Oct. 14 2011). For her, however, these two factors are unrelated. Based on the other activities in her life, grant support would not help in the production of her art; in fact, she rejected the notion of receiving a grant to help produce her material for fear that any outside financial input could change the scale on which she operates, indicating a potential risk to her autonomy and the symbolic capital invested in her work: "[A grant] might help me afford more of something, but I wouldn't do that anyway, you know? It's a limited run for a reason" (ibid.). With this statement, she signaled the value of scarcity as described by Bourdieu (1993, p. 117). Although her releases demonstrate physical scarcity through their limited quantities, they also possess cultural scarcity due to their role as handcrafted artifacts. Rebecca recognized this and clearly desired to have her releases remain as more autonomous goods rather than increase their quantities in hopes of entering a larger market. This sentiment reinforced the symbolic capital embedded within her work while simultaneously distancing itself from and subverting the economic motives that structure the mainstream industry.

Other musicians also found the issue of time to be a more significant challenge than the economic aspect of creating their work. Ashley described the challenge of balancing demanding non-musical activities, particularly a job that required large amounts of time and energy, with the production of her art (Ashley, personal interview, 
Oct. 14 2011). Without the ability to work continuously towards the completion of a project, she found herself being discouraged by the inefficiency of her creative production. Robert discussed similar challenges in having to adjust his creative time around multiple paid jobs, and this fragmented production schedule resulted in him being unable to truly hit his stride in the production of music (Robert, personal interview, Oct. 5 2011). With only "a few hours here and there" to work on his own creative projects, a lack of time was the factor that placed the greatest restriction on his artistic initiatives. Some of the participants who complained about a lack of time to devote to their music suggested that grants would help their situation by allowing them to reduce their working hours (Ashley, personal interview, Oct. 14 2011; Robert, personal interview, Oct. 5 2011). Others rejected the notion that grants would help to support them in the creation of art (Rebecca, personal interview, Oct. 4 2011). This oppositional stance demonstrates, perhaps, a desire to remain autonomous from the greater cultural support system as a way of adhering to the DIY mindset and the refusal to conflate time issues with the economic concerns that are the focus of the mainstream industry. For these artists, an increase of grant money would not solve their time shortage and they cited policy focus on community resources, such as accessible venues, as initiatives that would be more helpful to them. These two reactions to a lack of time demonstrate the tensions that exist between the needs artists express and what cultural policy portrays them as requiring to facilitate their musical work. 


\section{Releases: Aesthetics \& Distribution}

The development of social capital through shared experiences can also be observed in the production of recorded material. Since many artists working within restricted fields manufacture their own physical releases with help from other members of their community, these limited-edition runs of cassettes or CDRs can be seen as a physical embodiment of many of the symbolic factors that non-mainstream artists find valuable. Their restricted quantities and handcrafted nature do not make them ideal tools with which to accumulate financial capital, yet those same characteristics contribute to their scarcity as objects and thus increase the other types of capital they possess.

The small runs created by either independent labels, a group of collaborating artists, or one individual on his or her own reinforce the symbolic capital invested within musical objects. Their physical scarcity contributes to this form of capital, and the fact that these albums are often accompanied by elaborate packaging or artwork also heightens their symbolic value by framing a release as not only as a musical recording, but as a more complete cultural good. Because the process of manufacturing these releases is often time- and labour-intensive, this cuts down on the efficiency of production and does not make them ideal goods for the accumulation of economic capital. However, other members of a scene will recognize the efforts that go into a detailed aesthetic package and understand its value as a symbolic good. Ashley described her canon of material as being "mostly self-released where I'm making the artwork or collaborating with somebody to make the artwork and I'm making the physical copies, like dubbing the tapes in real time, one by one" (Ashley, personal interview, Oct. 14 
2011). While she did express some frustration regarding the labour-intensive nature of this process, she also mentioned the positive result of having every copy of a release be a unique object due to its handcrafted artwork. This kind of product would likely not be recognized for its full symbolic value within the larger market, but its position within a field that values autonomy and different types of capital results in a much greater appreciation for the work as a cultural good. Because most members of a scene tend to be involved with musical production in some way or another, the symbolic capital associated with these elaborate physical releases resonates with them. They can observe the packaging of a release and appreciate the time and energy that went into it, where these qualities may be less apparent within a larger field comprised of members who are unfamiliar with the efforts associated with DIY production.

Although Ashley was the only artist who went into detailed discussion of the intensive production process, an examination of the releases manufactured by many of the other interviewees leads to the conclusion that her experience is likely common amongst members of restricted fields. At least two-thirds of the participants have released tapes and CDRs that display these traits of high symbolic value: albums are duplicated in small runs (sometimes one at a time), their sleeves are painted or silkscreened by hand, and inserts are carefully drawn or designed by the artist or a visual collaborator. The symbolic value that results from these characteristics may become increasingly important given that much of today's music is easily available online, so the packaging of a release as not only a musical good but as a more complete aesthetic product with a visual or tactile component could play an even more significant role as these artists attempt to 
reinforce their creative autonomy and the non-economic capital invested in their work. As a result, many experimental artists develop a skill-set that encompasses visual artistic abilities as well as musical ones to facilitate the creation of their releases. This DIY process of putting together releases and their packaging also signals a sense of aesthetic freedom that is likely much harder to maintain once an artist begins working on a mainstream level. Since the participants and their peers generally maintain full autonomy over their work, they do not have to bend to the influence of managers, labels, or other forces that could assert aesthetic control, as tends to be the case for artists who work on a larger or more commercial scale.

In part due to the small runs of material that they produce, most of the artists I talked to only sell their music within local shops or as merchandise during live performances. However, even if they were interested in stocking their music into shops on a more widespread basis, the struggle of establishing a distribution deal often renders this task challenging, if not impossible. Many of the participants stressed the difficulties they have experienced in dealing with music distributors, especially in recent years ${ }^{20}$. It is widely known throughout the music business that the changing nature of the industry has put increasing amounts of stress on different players within the larger field of music production, with distributors being one of the hardest-hit entities. This has made it even more difficult for artists to disseminate their work effectively, especially those working in less commercially-viable styles. Consequently, those who are interested in making their

\footnotetext{
${ }^{20}$ Legendary independent label Touch \& Go shut its distribution services in 2009. This move was highly lamented within the music industry and many saw it as a general indicator of the future for physical distribution. See http://www.billboard.biz/bbbiz/indies/touch-go-to-cease-new-signings-distribution1003942590.story and http://latimesblogs.latimes.com/music blog/2009/02/touch-go-to-cut.html.
} 
music available to a wider range of audiences have faced increasing amounts of difficulty finding any sort of legitimate distribution. Brian, who runs his own small record label, described the issue of distribution to be one of the key challenges he faced: "The struggle with the label was how do we get distribution, and then we got distribution and it collapsed. The whole industry has collapsed" (Brian, personal interview, Oct. 132011 ). This quote was prompted by his experience of having deals established with four distributors and then watching three of them shut down over a short period of time, leaving both his band and his label struggling to maintain the availability of their music to audiences across the country.

Not only does the lack of distributors mean that independent artists and small DIY labels are scrambling to maintain the accessibility of their music for geographically remote listeners, it also indicates the increasing challenge of gaining recognition for one's project in the eyes of larger institutions. Many artists are not considered to be fully serious about their craft until they have established some type of distribution deal. In addition to providing physical circulation of their recorded material, a distribution agreement demonstrates a commitment to the traditional act of getting one's album into stores and making them available for purchase, leading to the accumulation of economic capital. This may be part of the reason why many large institutions, including granting organizations, use distribution or number of records "moved" or sold as a litmus test of an artist's dedication to his or her practice. An example of this can be seen in the FACTOR Loan program, which requires artists to have "a fully executed distribution deal with a FACTOR recognized distributor at the time of applying" unless they have sold at 
least 2000 units of their latest release (FACTOR Frequently Asked Questions, http://www.factor.ca/FAQSubmissions.aspx).

Striking these deals with distributors is becoming increasingly challenging due to the shrinking number of companies providing these services ${ }^{21}$. "Physical distribution is completely just shutting down all over the place. I mean, it still exists, but the levels that it's happening on are completely changing," Rebecca explained when asked about her experience with previous attempts to get her music distributed (Rebecca, personal interview, Oct. 4 2011). Chris also discussed how the difficulties in establishing distribution for his music can have a more widespread impact on other activities within the overall process of working creativity in the field: "If you don't have distribution, it's hard to get your music out there to people, so that you get maybe more show opportunities or more people listening to the record" (Chris, personal interview, Oct. 3 2011). For Brian, one of the most difficult aspects of distribution was the process of finding a distributor that understands his desire to favor community and cultural achievement over financial gains. He claimed that one of the most beneficial forms of support that could be enacted for him as an artist would be the introduction of "distribution that is not secretly hoping that it becomes a major distribution outlet that's actually willing to be sensitive to communities and promote a wide variety of work" (Brian, personal interview, Oct. 13 2011). For him, the acceptance of diverse aesthetics and artistic autonomy is key and as a result he has found himself at odds with the highly

\footnotetext{
${ }^{21}$ Allison Outhit wrote a column in the August 2009 edition of Exclaim! magazine outlining the current position of distribution companies in Canada and how their struggles can impact artists. See http://exclaim.ca/MusicSchool/NeedToKnow/what_distributors_are_looking_for.
} 
profit-driven attitude that he has observed in many branches of the music industry, including some distributors.

As a result of these challenges in establishing distribution deals, many artists developed alternative ways of circulating their music. The internet, small independent distributors, or a complete lack of distribution are all tactics adopted by artists who were unable to strike a deal with a recognized distributor. However, the development of a distribution system that is accessible to artists who work in experimental styles (and thus tend to focus more heavily on accumulating symbolic and social capital than economic capital) was nonetheless a desire expressed quite vehemently by several of the participants.

For many of the artists I spoke with, distribution is seen not as a path to increasing economic gains through more sales of a physical good. Instead, they understand it largely as a strategy that will allow their music to be heard by a larger audience. This attitude allows them to retain their sense of autonomy as creators by focusing on the social elements and increased exposure that can come as a result of more widespread sharing of their work. Interestingly, while several of the artists mentioned exposure as a benefit of increased distribution, none brought up increased sales that may be facilitated by having their releases carried in a larger number of shops. This perception of what benefits are available through the distribution of their music reinforces the small role that economic gain plays for them when compared to being able to share their work with other individuals and potentially build connections with those audience members who appreciate their music. Consequently, even when experimental artists use (or attempt to 
use) some of the established tactics of the mainstream industry, they claim to approach them with different goals from those which are traditionally achieved as a result. As Jennifer stated, making money from the creative process would be a nice bonus but it is not a significant motivator for her (Jennifer, personal interview, Oct. 82011 ). Instead, these artists are focused on developing social capital within their scenes and encouraging creativity. This may reinforce the notion of rejecting the normative tropes of the industry through subverting the goal of economic gain with other types of capital as a means of autonomous self-defense against the presupposed idea of success perpetrated by the large-scale field.

While distribution was a struggle for many of the artists I talked to, gaining exposure was also an issue that was brought up by several artists as a hurdle they faced when working within their field. The changing nature of the music industry has led to a vast increase in the amount of creative action that can take place online, and that provides both opportunities as well as challenges for artists. Dan, an electronic musician who has extensive experience working with music in an online context, describes his difficulties in gaining any real attention from audiences simply based on the vast amount of content being circulated on the internet:

There's just too much out there. It's really difficult to catch anyone's attention because there's such a din of new artists constantly throwing stuff online ... How do you get noticed? That's a code I haven't cracked yet. I've been doing this for over a decade now, and I don't know how to get people's attention (Dan, personal interview, Oct. 16 2011).

What is particularly interesting about this example is that it is drawn from an artist who does not typically release physical products; his music is mostly available online, 
and his struggles with gaining the attention of audiences seems more pronounced than those expressed by other artists. At the same time, he placed less emphasis on the social capital within his scene because so much of his work and that of his peers takes place behind a computer screen and does not hinge upon the live performance of music to the same extent that it does for other musicians to whom I talked. This indicates a dynamic influenced by the tensions within a changing music industry; the move towards exclusively online music production and circulation may lead to a risk of diminishing social capital, and consequently could result in a lack of connection with audiences and other musicians. As well, the symbolic value that other artists described as being invested in their products are not nearly as evident within online music files. Since digital files lack the visual and tactile appeal that contributes to the overall symbolic capital of a work, some artists do not find it as appealing a format for circulating their own work. Yet, at the same time, the electronic artists I talked to seemed no more focused on gaining economic capital than those working in other genres. This may signal further confusions or tensions brought about by larger industry changes; these artists want exposure, but due to the lack of physical goods they produce and the overflow of artists releasing material online they struggle to get shows and develop a strong following.

The issue of exposure is not restricted to those using online tactics as a way of reaching audiences. Chris, who has worked in a variety of genres including multiple styles of electronic music, cited visibility as one of the key challenges he faces in the production of music (Chris, personal interview, Oct. 3 2011). Due to the difficulty in establishing distribution and the limited amount of touring he is able to do (one of his 
bands features many musicians so the cost of extensive touring is prohibitive; the other is a long-distance collaborative project which also hinders the ability to play live), achieving visibility among audiences outside his home scene is challenging. In addition to highlighting the importance of live performance in establishing social capital for experimental artists, this also demonstrates different issues that can impact the ability to reach an audience.

The internet may help to reach out to new areas but, as Dan described, the abundance of musicians vying for attention online makes it very difficult to be noticed. Additionally, connections that rely heavily on internet-based communication may not be as fulfilling as direct interpersonal interactions in terms of their social capital. The strong emphasis that many of the artists placed on social connections and their appreciation of the symbolic capital found within their physical goods stands somewhat at odds with an increased amount of internet activity. Instead of putting their efforts towards online outreach that could establish new audiences the majority of participants seemed more content to spend time working alongside peers, creating new musical works to share with other members of their scene and audiences abroad.

This tension between the reliance on new technology to reach audiences and the constant desire to maintain social capital within the scene was an issue that Rebecca identified as being very important to her band (Rebecca, personal interview, Oct. 4 2011). As the youngest member in a group that ranges. widely in age, she grew up largely having access to the Internet and sees it as a tool as opposed to a threat; however, other members who are older and lack the familiarity with online music practices are much more hesitant 
to use it for the promotion of their music. There is also a wariness stemming from the desire to remain separate from websites that have certain political or social connections. Rebecca identified one of her bandmates who is opposed to websites like MySpace and Facebook due to any corporate strings that may be attached and the fear of having their music being taken without fair compensation. However, for Rebecca, the Internet is an important tactic that can be used in spreading the word about their group:

The whole idea is that we need to get the music out there. People need to hear it. That's how we get shows, that's how people discuss us and then are like, 'we want to buy albums.' But there's also, in person we do need to poster, talk to people we know, be involved with community, find out when other people are doing things that we can play with them, things like that. So that's the big obstacle, is trying to balance these different things (Rebecca, personal interview, Oct. 4 2011).

Rebecca's explanation of the opportunities and fears that are associated with Internet use demonstrate the challenges that some artists face in terms of maintaining their sense of autonomy (by not relying on websites that they view as having undesirable corporate ties) and also striking a balance between their strong emphasis on social community in the physical sense (through the attendance of shows, for example) and the need to sit behind a computer and use technology to reach listeners. The increasingly large role that the Internet plays in cultural promotion may indicate a shifting sense of how social capital is developed, but for Rebecca's band they still value the face-to-face social nature of their scene over interpersonal connections that are facilitated by a computer -- and this sentiment was shared by several other participants in the study as well. 


\section{The Musician's Lifestyle: Touring and its Impacts, On and Off the}

\section{Road}

While there are obviously benefits associated with the ability to travel and perform for, or collaborate with, individuals outside one's home community, the act of touring also poses its own set of distinct challenges. Canada is known as a particularly difficult country in which to tour due to its expansive geography and harsh climate. When playing outside of the country, the process of getting a visa (if one is to follow the rules in terms of crossing international borders) is an arduous and often expensive task. Once on tour, financial expenses and physical wear on a musician's body can become issues as well. While this experience is not unique to artists working in experimental styles, the fact that their music generally does not appeal to large audiences tends to limit the financial earnings they accumulate while on tour more so than it might for artists who play within established mainstream styles. This results in experimental artists facing hardships or challenges that are not often experienced by mainstream pop or rock artists, thus separating their experience from the vision of touring that is typically discussed in broader cultural discourse. Nick, the guitarist in a noise rock band which has toured extensively through both North America and Europe, described the ways in which he and his collaborators survive on the road: "We're very careful. We never eat at restaurants, we strictly eat out of a cooler and shop at grocery stores ... We never stay at hotels, we always crash with kids, sleep on someone's floor" (Nick, personal interview, Oct. 14 2011). 
These experiences are the reality for the majority of bands working in a smallscale field of production. The vision of touring that Canadian policy organizations suggest with their descriptions of low-budget rooms and tour buses are not even a legitimate option for many artists who work outside mainstream genres. In The FACTOR Story, a quote from the band Mariana's Trench exemplifies the "dreary" vision of touring that policy makers subscribe to: "If you are an up-and-coming band, a good opening slot is about exposure. It's a series of $\$ 100$ shows. Between gas and food for four guys, $\$ 100$ is like petty cash. Sell some merch, and you might get your own bed that night" (The FACTOR Story, p. 4). Drawing from his own experience on the road, Nick described his reaction to artists with that stance towards touring and its reflection in the dominant discourse with a significant amount of disdain:

They can say that going out on tour is a huge fucking red ink write-off, you know? And that justifies it. The thing is, the money you get if you have direct board approval for touring is insane. It's like, you can $\$ 60$ per diems per artist. $\$ 60$ will feed a member of [my band] for fucking two weeks, if we had that much money. We do it so low to the ground, but we do it in a way so that we don't lose any money (Nick, personal interview, Oct. 14 2011).

Another challenge posed by the act of frequent touring is its impact on the time that musicians get to spend at home. The somewhat transient nature of an artist who travels frequently can lead to challenges in terms of finding paid employment that will accommodate this lifestyle. As a result, many who choose to spend time on tour are forced to simply take what they can get in order to make ends meet. Nick explained that due to his band's choice to tour so frequently, finding any sort of reliable employment has been extremely difficult: 
I've worked jobs that are bad for my [physical] health, I've worked jobs that are bad for my mental health because you can't, especially as a touring musician, you can't always find places to work, so you have to ... take what you can get. You really have to sacrifice basically everything (Nick, personal interview, Oct. 14 2011).

He described how some musicians do have an easier time with this, depending on their formal training and line of work; for instance, some of his peers who are self-employed as designers are able to set their own schedule and do not face the same problem of constantly searching for a short-term job to last until the next tour begins. Additionally, not all artists spend a significant amount of time touring the way his band does. Many have jobs, families, and other factors that limit the amount of time they are able to spend on the road. Living on the road for extended periods of time can put strain on these aspects of a musician's life -- on top of facing difficulties in terms of finding employment and being able to support oneself financially, the time away and its impact on one's lifestyle when he or she returns can have negative effects on the artist's health and social relationships. These factors are seldom taken into account in the somewhat romantic portrayal of a musician on the road; certainly in the model constructed by cultural policy literature, many of the realities faced by the artists I interviewed are not sufficiently acknowledged.

The typical vision of the artist also fails to recognize other basic difficulties that musicians face. While many institutions, including policy agencies, recognize that artists can struggle in financing the production of their art, it does not seem to be acknowledged that ordinary needs not directly related to the creation of their work may also require assistance. Nick elaborated on his discussion of touring by stating that its tolls on artists combined with unstable employment -- including jobs that can pose physical health risks 
-- has impacted his life and ultimately resulted in the desire for support not in the form of recording grants, but instead for health benefits such as a dental plan or eye care (Nick, personal interview, Oct. 14 2011). For him and his collaborators, the act of cultural production itself does not need funding but the individuals within that scene could largely benefit from simple healthcare initiatives.

The balance of gaining exposure outside of the immediate scene and finding time to work on creative projects while still maintaining their responsibilities within their own community, including employment, school, and families, was something that many participants mentioned as a difficulty during the interviews. Indeed, the very jobs that allow many of these artists to function as autonomous creators also serve to restrict the amount of touring they can do. Some of them were content to have music remain as more of a hobby that could be balanced with employment, while others were more interested in finding a way to sustain themselves financially from their music while still retaining their sense of autonomy. Ultimately, the commonality between the different participant accounts was that their experiences tended to differ quite significantly from the notion of touring that is perpetuated within the dominant music industry logic. There were no tour buses or hotel rooms, let alone profits of more than $\$ 100$ per show, for most of the participants I interviewed ${ }^{22}$. These differences of earnings and practices while on the road can have significant impacts on artists both during the tour and at home, and they

\footnotetext{
${ }^{22}$ Having let many touring bands stay at my home over the past eight years, I have observed the tendency to tour "low to the ground" as described by Nick among the vast majority of these artists. While the act of touring and its impacts was only discussed in detail by one participant, my own experiences corroborate his claims. The practice of eating out of a cooler and sleeping on the floor of a friend (or sometimes a stranger) is widespread among experimental artists, based on my own personal observations.
} 
ultimately signal a disjuncture between the discourse and the realities experimental artists face.

\section{A Summary: General Trends and Findings}

Drawing from the participant interviews, there were a number of key components that shaped the scenes in which experimental artists work. Issues of community, space, time, aesthetics, and the lifestyle that facilitates touring and other musical activity all contributed to the experiences that these artists face. Community was one of the most important elements that the participants discussed, and given the small scale and tightknit nature of their scenes there was a distinct emphasis on its value to artists. The ability to collaborate with and draw support from other musicians within one's scene was spoken of very highly, and many participants indicated that the sense of community within a scene had the potential to be either extremely positive or very challenging. What was particularly interesting about this participant feedback was the magnitude of such an ephemeral quality on a scene and its members. Community is a component of the scene that is difficult to quantify and, when discussed in the context of localized practices, is curiously absent from the majority of discourse surrounding Canadian music production.

Space was also mentioned as a factor which influenced the way artists were able to create and share their music, and its impact varied widely based on elements of social and urban geography. In particular, the challenge of finding accessible venues was an issue many participants raised with regard to space and how it can structure their actions. Many of the interviewees described their challenges in terms of finding venues that would accommodate their work based on its aesthetic nature and the knowledge that it 
would not draw as large a crowd as more mainstream genres might. The spaces that tend to be most open to the sonic experiments that some of the participants engage in are often unofficial venues that generally do not serve as long-term, sustainable venues due to legality, neighborhood complaints, rent increases, and any number of other factors that can cause underground art spaces to shut down.

Given that all of the participants balanced at least one job with the production of their music, time was another factor that many of them described as having a significant impact on their creative processes. Some of them suggested that being able to devote longer consecutive stretches of time to their music would increase their productivity, and it was generally these artists who had made the most attempts to apply for grants in the past. While some of these applications were successful, none of the artists I talked to were able to fully support themselves on a long-term basis through the production of their art, even when combined with grants or other cultural support funds. In contrast to this, some artists were very adamant about the fact that an increase in money through grants would not necessarily ease the lack of time they felt restricted their musical productivity. Regardless of this difference in stances, all of the participants were clear about their position as working individuals whose creative activity is not their primary source of income, which provides a contrast from the general framing of artists within literature about Canadian music.

The way that the participants described their musical releases challenges many of the conceptions surrounding production of mainstream albums within the national industry. Since the participants mostly release material in small runs, often assembled by 
hand and featuring elaborate packaging, these albums serve as more than simply musical products -- their visual and tactile elements render them artifacts embedded with high levels of symbolic capital. This differentiates them from the mass-produced albums that are created by mainstream artists, and the participants generally took great pride in the efforts that went into their releases.

Finally, adopting a lifestyle that accounts for touring and the other activities of musicians was a major element that structured the experiences of my participants. This impacted their health, employment, and social relations both on and off the road. Some artists were unable to tour due to jobs or family commitments, while others made sacrifices in those areas in order to allow traveling with their bands. The participants who spent extensive time touring also struggled the most with financial difficulties, mostly due to their restricted work schedule, and this in turn had negative impacts on other facets of their livelihood. 


\section{Conclusion}

Based on the attributes of their scenes that these artists articulated, the challenges they face and the benefits they reap differ significantly from the vision typically presented by academics and policy institutions. Financial gain is not of primary importance (nor is it a realistic option); instead, they struggle with other factors that are rarely acknowledged in the structure of cultural policy or the larger discourse surrounding Canadian musicians. Health, employment, venues, and community are the key issues for many small-scale cultural producers throughout the country. And while these factors may represent significant difficulties for artists, some of them also hold the potential to be extremely rewarding if approached in the right way. Issues such as accessible venues and community involvement can prove highly beneficial to the activity of a scene by facilitating increases in social, cultural, and symbolic capital. While these elements represent important parts of the scenes in which artists work, their attention within Canadian music discourse is lacking.

Drawing from the interviews, it became evident that the experimental artists I talked to and the intricacies of their scenes are largely absent from the dominant logic of music as a field of production. Their focus on developing social, cultural, and symbolic capitals instead of economic capital stems from a sense of autonomy from the larger market. In addition to this, their accounts challenge some established conceptions about Canadian musicians: that grants and cultural funding open many doors for them and play a significant role within their creative process, that they are influenced by American mass culture through a desire to succeed with markets south of the border, and that their 
ultimate goal is to achieve large-scale financial earnings through their music. Instead, the participants described a picture of their scene in which economic gain was often seen as a bonus that could come in addition to the benefits of working alongside respected musicians and contributing to projects that they deemed culturally and symbolically important. This represents an inversion of artists' priorities as they are represented in the dominant discourse surrounding the Canadian music industry.

Structuring the vision of the artist around the first-hand accounts of cultural creators themselves instead of working from a policy basis provides new understandings of Canadian musical production that are seldom acknowledged within the discourse surrounding the mainstream industry. By mobilizing the concepts of the scene and noneconomic forms of capital as ways of helping to map out the varying structures that contribute to musicians' experiences, we are able to gain a more thorough comprehension of how and why artists make the choices they do. Certain practices in which experimental artists engage overlap with the standard activities encouraged by the mainstream industry, such as releasing albums and playing live, but the motivations behind these practices often differ significantly from those embraced by mainstream musicians. While the mainstream industry is driven primarily by economic forces, the participants in my study revealed that they are generally more focused on accumulating other types of capital through the creation and dissemination of their work. Social, symbolic, and cultural capital were typically valued more highly than mass economic gains within experimental music scenes, which illustrates a very different dynamic from that which is found within the mainstream industry and the literature surrounding it. Experimental musicians are not 
defined in the same economic terms or framework, and it is only by listening to their experiences that we can begin to develop a better understanding of how they function as cultural creators. Additionally, the value in talking to artists is not restricted to those who work in experimental or niche genres; on the contrary, the richness provided by the participants within my study suggests that it could also be worthwhile to engage directly with musicians in other styles, including mainstream genres, to determine the extent to which their experiences are accounted for within the logic of the national industry.

My findings also raise other issues that merit further investigation. For instance, a study looking into the sense of community that is found within particular music scenes would be valuable due to its importance as suggested by the participants. How is this sense of community maintained in non-event contexts? How do new members to the scene become accepted into the community? Are there any activities or gestures that signal one's membership? These are the types of questions that stem from the discussion generated by the participants. Addressing these issues, as well as looking into the importance of non-economic capital and other tropes which differentiate experimental music scenes from the logic of the mainstream industry, would all contribute to the development of a more complete understanding of musical production and the realities lived by artists within these scenes.

Giving artists the opportunity to discuss their challenges, opportunities, and the other realities they face highlights many different issues that receive little, if any, discussion within the mainstream industry. The difficulty of finding suitable venues, fostering community involvement, and balancing musical practice with the demands of 
daily life are all elements which structure the ways artists function, but their influence is rarely acknowledged within literature about Canadian music. On a similar token, the benefits of strong social connections within a scene and the act of contributing to a symbolically-rich local music community can be highly rewarding, yet these factors are also largely absent from the discussion on Canadian music.

These differences that set local music scenes apart from the mainstream industry are key factors that challenge many of the established ideas about Canadian music and the ways in which it is produced. Despite the strong focus on policy throughout much of the literature surrounding mainstream cultural production and its reactions towards American influence, the participants in this study felt little impact from the policy initiatives which are generally thought of as being strongly interconnected with the nation's music production. These findings suggest that the participants do not fit neatly into the mould of the artist that is typically portrayed by the industry and its literature and, consequently, they call for a re-thinking of the ways in which Canadian musicians are framed. My study provides a mere glimpse into the realities of experimental artists, but even the resulting preliminary findings are enough to signal a disjuncture between traditional conceptions of the artists and the experiences that are lived by those working in highly localized scenes. The act of giving voice to the artists themselves and allowing them to describe their practices and environments provides a highly valuable account of what it means to be a musician in the contemporary Canadian environment. Although further research is necessary to develop a more elaborate understanding of experimental artists and their practices, the insight gained from the participants displays the value of 
constructing our understanding of musicians from their own first-hand experiences. The focus on artists' perspectives provides a necessary break from the rooting of Canadian music within policy discourse and nationalistic efforts, and it is this emphasis on the localized, unique voices within the country's music scenes that deserves greater attention in the future. 


\section{Works Cited}

Allmusic.com. "Experimental Electro."

http://allmusic.com/explore/style/experimental-electro-d3045

Bennett, Tony. (Dec. 1993). Rock and Popular Music: Politics, Policies, Institutions. Eds. Tony Bennett et al. London: Routledge.

Berland, Jody, and Will Straw. (1995). Getting Down to Business: Cultural Politics and Policies in Canada. In Benjamin D. Singer (Ed.), Communications in Canadian Society, Fourth Edition (pp. 332-356). Scarborough: Nelson Canada.

Bourdieu, Pierre. (1986). The Forms of Capital. In J.F. Richardson (Ed.), Handbook of Theory Research for the Sociology of Education. (pp. 241-258). Translated by Richard Nice. Connecticut: Greenwood Press.

Bourdieu, Pierre. (1993). The Field of Cultural Production. Cambridge: Polity Press.

Bourdieu, Pierre. (1984). Distinction: A Social Critique of the Judgement of Taste. Translated by Richard Nice. Cambridge: Harvard University Press.

Brooker, Joe. (Autumn 2003). Commercial Alternative. New Formations, 50, 106-122.

Crean, Susan. (Fall 2000) Looking back to the future -- Creators and cultural policy in the era of free trade: A Commentary. Journal of Canadian Studies 35.3, 199-212.

Dept. of Canadian Heritage. (2007). The Canadian music industry 2006 economic profile. Gatineau: Canadian Heritage.

Dowler, Kevin. (1996). The Cultural Industries Policy Apparatus. In Michael Dorland (Ed.), The Cultural Industries in Canada. (pp. 328-346). Toronto: James Lorimer \& Company.

Edwardson, Ryan. (2008). Canadian Content: Culture and the Quest for Nationhood. Toronto: University of Toronto Press.

FACTOR. "Frequently Asked Questions." http://www.factor.ca/FAQSubmissions.aspx

FACTOR 2010-2011 Annual Report. www.factor.ca.

FACTOR. (2007). The FACTOR Story. 
Garofalo, Reebee. (1991). The internationalization of the US music industry and its impact on Canada. Cultural Studies, 5.3, 326-331.

Gracyk, Theodore. (2001). I Wanna Be Me: Rock Music and the Politics of Identity. Philadelphia: Temple University Press.

Grenier, Line. (April 1990). Radio Broadcasting in Canada: The Case of 'Transformat' Music. Popular Music, 9(2), Radio Issue, 221-233.

Henderson, Scott. (May 2008). Canadian content regulations and the formation of a national scene. Popular Music, 27(2), 307-315.

Hesdmondhalgh, David. (December 2008).Towards a critical understanding of music, emotion and self-identity. Consumption, Markets \& Culture, 11(4), 329-334.

Iles, Anthony. (2009). Introduction. In Mattin and Anthony lles (Eds.), Noise \& Capitalism. (pp. 8-17). San Sebastian: Gipuzkoako Foru Aldundia-Artelekuw.

Jones, Steve. (1990). The cassette underground. Popular Music and Society, 14(1), 75-84.

Leslie, Larry Z. (2010). Communication Research Methods in Postmodern Culture: A Revisionist Approach. Boston: Allyn \& Bacon.

Lorimer, Rowland, and Mike Gasher. (2004). Mass Communcation in Canada, Fifth Edition. Don Mills, Ontario: Oxford University Press.

Markus, György. (August 2006). Adorno and Mass Culture: Autonomous Art Against the Culture Industry. Thesis Eleven 86, 67-89.

Mauws, Michael. (June 2000) But Is It Art?: Decision Making and Discursive Resources in the Field of Cultural Production." The Journal of Applied Behavioral Science 36(2), 229-244.

Moore, Ryan. (2007). Friends don't let friends listen to corporate rock: Punk as a field of cultural production. Journal of Contemporary Ethnography, 36(4), 438-474.

Nordicity Group. (1995). Task Force on the Future of the Canadian Music Industry. Ottawa: Nordicity Group Ltd.

O'Connor, Alan. (2008). Punk Record Labels and the Struggle for Autonomy: The Emergence of DIY. Lanham: Lexington Books, 2008.

Outhit, Allison. (August 2009). What Distributors Are Looking For. Exclaim Magazine. http://exclaim.ca/MusicSchool/NeedToKnow/what distributors are looking for. 
Papizzo, Brian O'Shea. (1994). Towards a political economy of the Canadian recording industry. Ottawa: Carleton University (M.A. thesis).

Raboy, Marc. (2006). Creating the Conditions for Communication in the Public Good. Canadian Journal of Communication, 31(2), 289-306.

Russell, Bruce. (2009). Towards a Social Ontology of Improvised Sound Work. In Mattin and Anthony Iles (Eds.), Noise \& Capitalism (pp. 72-95). San Sebastian: Gipuzkoako Foru Aldundia-Artelekuw.

Sanderson, Paul. (1985). Musicians and the Law in Canada. Toronto: Carswell.

Spalding, Eric. (Spring 2008). Twice Born: The Origins of the Foundation Assisting Canadian Talent on Recordings (FACTOR), 1982-86. Journal of Canadian Studies, 42(2), 140-161.

Shank, Barry. (1994). Dissonant Identities: The Rock'n'Roll Scene in Austin, Texas. Hanover: University Press of New England.

Stahl, Geoff. (2001). Tracing out an Anglo-Bohemia: Musicmaking and Myth in Montréal." public, 22-23: Cities/Scenes, 99-121.

Statistics Canada. (2009). Sound Recording and Music Publishing Service Bulletin.

Strachan, R. (2007). Micro-independent record labels in the UK: Discourse, DIY cultural production and the music industry. European Journal of Cultural Studies, 10(2), 245-265.

Straw, Will. (1996). The Cultural Industries in Canada. In Michael Dorland (Ed.), The Cultural Industries in Canada. Toronto: James Lorimer \& Company, Publishers.

Straw, Will. (2004). Canadian Radio and the Music Industry. Museum of Broadcast Communications Encyclopedia of Radio, 1, 278-279.

Straw, Will, and Richard Sutherland. (2007). The Canadian Music Industry at a Crossroads. In David Taras et al. (Eds.), How Canadians Communicate II: Media, Globalization and Identity (pp. 141-165). Calgary: University of Calgary Press.

Straw, Will. (2001). Scenes and Sensibilities. public, 22-23: Cities/Scenes, 245-257.

Straw, Will. (1992). The Music Industries in Canada. In The Encyclopedia of Music in Canada, 2nd ed. Toronto: University of Toronto Press. 
Straw, Will. (Fall 2000). In and Around Canadian Music. Journal of Canadian Studies, 35(3), 173-184.

Straw, Will. (Autumn 2004). Cultural Scenes. Loisir et société/Society and Leisure, 27(2),411-422.

Toth, Csaba. (2009). Noise Theory. In Mattin and Anthony lles (Eds.), Noise \& Capitalism (pp. 24-37). San Sebastian: Gipuzkoako Foru AldundiaArtelekuw.

Valentine, Jeremy. (Spring 2007). Political Art, Cultural Policy, and Artistic Agency. Social Analysis, 51(1), 96-111.

Van Veen, Tobias. (2003). Fuck Art, Let's Dance. FUSE, 26(3), 12-19.

Vincent, Andrew. (2005). Making Scenes: Studying Local Independent Music in Canada. Ottawa: Carleton University (M.A. thesis).

Wagman, Ira. (2001). Rock the Nation: MuchMusic, Cultural Policy and the Development of English-Canadian Music-Video Programming, 1979-1984. Canadian Journal of Communications, 26(4), 47-62.

Wagman, Ira. (2010). On the Policy Reflex in Canadian Communication Studies. Canadian Journal of Communications, 35(4), 619-630.

Watson, Ben. (2009). Noise as Permanent Revolution. In Mattin and Anthony Iles (Eds.), Noise \& Capitalism (pp. 104-122). San Sebastian: Gipuzkoako Foru AldundiaArtelekuw.

Wikipedia.com. "Drone Music." http://en.wikipedia.org/wiki/Drone_music.

Wright, Robert. (1991). 'Gimme shelter': Observations on cultural protectionism and the recording industry in Canada. Cultural Studies, 5(3), 306-316. 


\section{Personal Interviews}

“Ashley," Montreal artist, October 142011.

"Brian," Ottawa artist and label manager, October 132011.

“Chris," Ottawa artist, October 32011.

"Dan," Ottawa artist, October 162011.

"James," Ottawa artist, October 22011.

“Jennifer," Montreal artist, October 82011.

"Mike," Ottawa artist, October 22011.

"Nick," Montreal artist, October 142011.

"Paul," Gatineau artist and label manager, October 32011.

"Rebecca," Ottawa artist, October 42011.

"Robert," Gatineau artist, October 52011. 


\section{Carleton \\ UN V V RSITY}

Canada's Capital University
Carleton University Research Office

Research Ethics Board

$5^{\text {th }}$ Floor Tory Bullding

1125 Colonel By Drive

Ottawa, ON K1S 5B6 Canada

Tel: $613-520-2517$

Fax: $613-520-2521$

athics@carteten.ca

\section{Ethics Clearance Form}

This is to certify that the Carleton University Research Ethics Board has examined the application for ethical clearance. The REB found the research project to meet appropriate ethical standards as outlined in the Tri-Council Policy Statement: Ethical Conduct for Research Involving Humans and, the Carleton University Policies and Procedures for the Ethical Conduct of Research.

\section{$X$ New clearance \\ - Renewal of original clearance}

\section{Original date of clearance:}

Date of clearance

Researcher

Status

Supervisor

Funding status

Project number

Title of project

Clearance explres: 31 May 2012

12-0606
19 September 2011

Joni Sadler

M.A. student, School of journalism and Communication

Professor Sheryl Hamliton, School of Journalism and

Communication

Non-funded

Working outside the mainstream: Experimental music and

Canadian cultural policy

\section{All researchers are governed by the following conditions:}

Annual Status Report: You are required to submit an Annual Status Report to either renew clearance or close the file. Fallure to submit the Annual Status Report will result in the immediate suspension of the project. Funded projects will have accounts suspended until the report is submitted and approved.

Changes to the project: Any changes to the project must be submitted to the Carleton University Research Ethics Board for approval. All changes must be approved prior to the continuance of the research.

Adverse events: Should any participant suffer adversely from their participation in the project you are required to report the matter to the Carleton University Research Ethlcs Board. You must submit a written record of the event and indicate what steps you have taken to resolve the situation.

Suspension or termination of clearance: Failure to conduct the research in accordance with the principles of the Tri-Councll Policy Statement: Ethical Conduct for Research Involving Humans and the Carleton University Policies and Procedures for the Ethical Conduct of Research may result in the suspension or termination of the research project.

Antonio R. Gualtierl, Chair

Carleton University Research Ethics Board 